\title{
Quasi-biennial oscillation of the tropical stratospheric aerosol layer
}

\author{
R. Hommel ${ }^{1, *}$, C. Timmreck ${ }^{1}$, M. A. Giorgetta ${ }^{1}$, and H. F. Graf ${ }^{2}$ \\ ${ }^{1}$ Max Planck Institute of Meteorology, Hamburg, Germany \\ ${ }^{2}$ Department of Geography, Centre for Atmospheric Science, Cambridge University, Cambridge, UK \\ * now at: Institute of Environmental Physics (IUP), University of Bremen, Bremen, Germany
}

Correspondence to: R. Hommel (rene.hommel@iup.physik.uni-bremen.de)

Received: 16 April 2014 - Published in Atmos. Chem. Phys. Discuss.: 20 June 2014

Revised: 23 April 2015 - Accepted: 27 April 2015 - Published: 21 May 2015

\begin{abstract}
This study describes how aerosol in an aerosolcoupled climate model of the middle atmosphere is influenced by the quasi-biennial oscillation (QBO) during times when the stratosphere is largely unperturbed by volcanic material. In accordance with satellite observations, the vertical extent of the stratospheric aerosol layer in the tropics is modulated by the QBO by up to $6 \mathrm{~km}$, or $\sim 35 \%$ of its mean vertical extent between 100-7 hPa (about 16-33 km). Its largest vertical extent lags behind the occurrence of strongest QBO westerlies. The largest reduction lags behind maximum QBO easterlies. Strongest QBO signals in the aerosol surface area (30\%) and number densities (up to $100 \%$ e.g. in the Aitken mode) are found in regions where aerosol evaporates, that is above the $10 \mathrm{hPa}$ pressure level $(\sim 31 \mathrm{~km})$. Positive modulations are found in the QBO easterly shear, negative modulations in the westerly shear. Below $10 \mathrm{hPa}$, in regions where the aerosol mixing ratio is largest $(50-20 \mathrm{hPa}$, or $\sim 20$ $26 \mathrm{~km}$ ), in most of the analysed parameters only moderate statistically significant QBO signatures $(<10 \%)$ have been found.
\end{abstract}

QBO signatures in the model prognostic aerosol mixing ratio are significant at the $95 \%$ confidence level throughout the tropical stratosphere where modelled mixing ratios exceed $0.1 \mathrm{ppbm}$. In some regions of the tropical lower stratosphere the QBO signatures in other analysed parameters are partly not statistically significant. Peak-to-peak amplitudes of the QBO signature in the prognostic mixing ratios are up to twice as large as seasonal variations in the region where aerosols evaporate and between 70-30 hPa. Between the tropical tropopause and $70 \mathrm{hPa}$ the $\mathrm{QBO}$ signature is relatively weak and seasonal variations dominate the variability of the simulated Junge layer. QBO effects on the upper lid of the tropical aerosol layer turn the quasi-static bal- ance between processes maintaining the layer's vertical extent into a cyclic balance when considering this dominant mode of atmospheric variability. Global aerosol-interactive models without a QBO are only able to simulate the quasistatic balance state. To assess the global impact of stratospheric aerosols on climate processes, those partly nonlinear relationships between the $\mathrm{QBO}$ and stratospheric aerosols have to be taken into account.

\section{Introduction}

The stratospheric aerosol layer, also referred to as the Junge layer (Junge et al., 1961), is a key constituent in the Earth's atmosphere. The Junge layer plays an important role in the determination of the Earth's radiation budget and interacts with the cycles of chemically induced ozone depletion in the polar winter stratosphere. It is generally believed to be maintained by the oxidation of tropospheric sulfur dioxide $\left(\mathrm{SO}_{2}\right)$ and carbonylsulfide (OCS), entering the stratosphere by troposphere-stratosphere exchange processes (Holton et al., 1995; Fueglistaler et al., 2009), and by direct injections of volcanic material from modest to large volcanic eruptions (SPARC/ASAP, 2006; Bourassa et al., 2012). During times of low volcanic activity, the stratospheric aerosol load inevitably degrades towards a so-called background state representing the lowest possible self-maintaining aerosol level in the stratosphere. However, this natural balance may be influenced by sulfur-releasing anthropogenic activities (Hofmann et al., 2009; Neely et al., 2013). Together with the sporadically occurring volcanic perturbations, human activities alter the Earth's radiative balance, in turn affecting the longterm trend of the global aerosol load (Solomon et al., 2011). 
The relative contributions of the precursors to maintain the background Junge layer as well as their major pathways into the stratosphere (apart from direct injections by volcanoes) are not well understood (e.g. Hofmann, 1990; Deshler et al., 2006; SPARC/ASAP, 2006; Hofmann et al., 2009; Bourassa et al., 2012; Brühl et al., 2012; Rex et al., 2012; Neely et al., 2013).

With respect to the much-debated potential to moderate climate change by manipulating the Earth's albedo due to the enhancement of the stratospheric aerosol load, e.g. the Royal Society Report on Geoengineering the Climate (Society, 2009) explicitly emphasised a considerable demand to better understanding the spatio-temporal variability of the stratospheric aerosol system, including the barely explored coupling between the dynamics of the upper troposphere and lower stratosphere (UT/LS) and microphysical processes which ultimately determine load, size and stability of this system. Our study addresses in particular the latter issues as we will explain below.

A variety of fundamental questions of the stratospheric aerosol system have been addressed in the review of stratospheric aerosol processes by the WMO/SPARC initiative (SPARC/ASAP, 2006). The report focused on conditions observed after the powerful eruption of Mount Pinatubo in 1991, which significantly influenced both the stratosphere and the Earth's climate in the subsequent 2 to 3 years. SPARC/ASAP (2006) also revealed a few remarkable scientific issues related to stratospheric background conditions. For instance, the report emphasised that measured LS aerosol quantities distinctly differ between the observational systems (in situ, remote). More recent studies addressed this problem in several ways (e.g. Thomason et al., 2008; Damadeo et al., 2013) but since the decommissioning of the ERBS satellite in 2005, which hosted the SAGE II instrument, equivalently well examined data sets of vertically resolved stratospheric aerosol size properties do not exist.

Another major uncertainty of the stratospheric aerosol system arises from the lack of observations of the precursors $\mathrm{SO}_{2}$ and $\mathrm{H}_{2} \mathrm{SO}_{4}$ vapour in the stratosphere. $\mathrm{SO}_{2}$ and $\mathrm{H}_{2} \mathrm{SO}_{4}$ vapour quantities have not yet been systematically monitored in the LS - contrary to the troposphere, in particular the boundary layer. Only a few individual measurements of the two gases were conducted in the stratosphere during balloon ascents in the 1970s and 1980s (see Hommel et al., 2011, herein referred to as HOM11, for a review). Only a single remotely sensed $\mathrm{SO}_{2}$ profile existed for altitudes above $30 \mathrm{~km}$, obtained during a NASA Space Shuttle mission in 1986 (Rinsland et al., 1995) until very recently - a new $\mathrm{SO}_{2}$ data set has now been derived from Envisat/MIPAS observations (Höpfner et al., 2013).

With respect to modelling initiatives aiming to better understand the stratospheric aerosol-climate system, there has also scarcely been any progress since SPARC/ASAP (2006) emphasised distinct differences between modelled aerosol quantities and observations. Most studies of global climate models with interactively coupled aerosol size and microphysics schemes focus on the examination of the tropospheric aerosol-climate system, predominately detached from stratospheric aerosol processes (Ghan and Schwartz, 2007; IPCC, 2013). Only a very limited number of studies addressed aerosol processes in the UT/LS by means of aerosol size resolving microphysics models that have been interactively coupled to global climate models. Some studies focused on the determination of aerosol induced climate effects of the Mount Pinatubo eruption 1991 (Niemeier et al., 2009; English et al., 2013). Other studies investigated the stability of the Junge layer during the stratospheric background periods (Timmreck, 2001; Pitari et al., 2002; Hommel et al., 2011; English et al., 2011; Brühl et al., 2012; Campbell et al., 2014).

In this study we address certain aspects of the coupling between stratospheric dynamics and aerosol microphysical processes, as they are important to understand the contributions of quasi-biennial oscillation (QBO) and natural variability to recent observed changes of stratospheric aerosol, and as they are key to evaluate stratospheric geoengineering options. We focus on effects imposed by the QBO in the tropical stratosphere (reviewed in Baldwin et al., 2001) as this dominant mode of stratospheric variability largely impacts the global dispersion of stratospheric trace constituents (e.g. Gray and Chipperfield, 1990). In particular we address the QBO signatures in the aerosol mixing ratio, in the integral and resolved aerosol size as well as in the abundance of aerosol precursors. Furthermore, we estimate the QBO signal in microphysical processes determining the transfer of sulfur mass between the gas and aerosol phases, i.e. nucleation and condensation/evaporation.

We elaborate a numerical experiment to simulate an 11year stratospheric background period after 1995, when the stratosphere had recovered from the violent eruption of Mount Pinatubo in June 1991 (SPARC/ASAP, 2006). This is done by coupling an aerosol size resolving microphysics scheme (SAM2; HOM11) and a middle-atmosphere circulation model (MAECHAM5; Manzini et al., 2006) that precisely specifies the QBO (Giorgetta and Bengtsson, 1999). To avoid any interference with effects superimposed from other external sources, the model is driven in a climatological mean configuration and does not consider any volcanic or pyro-cumulonimbus injections into the stratosphere. The analysis focuses on the spatio-temporal evolution of the Junge layer in the tropics, because the QBO signature is strongest in the equatorial belt. Modelled aerosols do not radiatively feed back to the general circulation and the QBO, neither directly nor by impacting the stratospheric ozone chemistry. Both may be important in particular for the extratropics and are in the scope of following studies.

Although stratospheric aerosols have been monitored with sufficient global coverage since the end of the 1970s, QBO signatures in observed post-Pinatubo stratospheric background aerosol quantities have only been inferred in a very 
limited number of studies (Choi et al., 1998, 2002; Barnes and Hofmann, 2001). Since these studies do not show QBO signatures in other aerosol quantities than the retrieved extinction coefficients or the aerosol backscatter, in this study we also infer QBO signatures from climatologies of the aerosol surface area density inferred from SAGE II retrieved extinction coefficients, in order to establish a direct comparison between our modelled aerosol properties and observations. In a consistent manner we also compare QBO signatures in $\mathrm{SO}_{2}$ observed by MIPAS (Höpfner et al., 2013) with our simulation.

We want to emphasise that the focus of our paper is the QBO-aerosol microphysics relationship and not an analysis of the stratospheric aerosol record as observed in the recent past. Other studies indicated the relevance of non-sulfate and mixed aerosols, for instance meteor debris (reviewed in Neely et al., 2011), volatile organics (e.g. Froyd et al., 2009) or carbon (e.g. Murphy et al., 2007), for the stratospheric aerosol burden, optical depth, and the radiative forcing. Here we focus on sulfate aerosols because they clearly dominate the stratospheric aerosol mass (see SPARC/ASAP, 2006). An understanding of the mechanisms determining the variability of the main reservoir of stratospheric aerosol is mandatory in order to separate the signatures of atmospheric dynamics, microphysics and volcanoes from the observed LS aerosol record in future studies. In this respect, our work can be seen as a necessary step towards an in-depth understanding of the lower stratospheric aerosol system by utilising a model system of reduced complexity.

The paper is structured as follows: first we give a brief overview about the model used in this study. The following sections describe the influence of the QBO on a variety of modelled aerosol parameters, size distributions and on the precursor gases $\mathrm{SO}_{2}$ and $\mathrm{H}_{2} \mathrm{SO}_{4}$ in the equatorial stratosphere. Our results are compared with other data from observations and models. The final section summarises our findings.

\section{Methodology}

\subsection{Model framework}

The model framework used to assess the interannual variability of the aerosol layer in the tropical stratosphere during times of stratospheric background is identical to the model described in detail in HOM11. In this study a middleatmosphere general circulation model with an interactive, particle size-resolved aerosol dynamics module was evaluated against satellite data and in situ observations. The major difference between the companion study of HOM11 and this work is the representation of the quasi-biennial oscillation in the equatorial stratosphere. While our applied model setup has no internally generated QBO (Giorgetta et al., 2002, 2006), we perform an additional experiment in which the
QBO is nudged towards observed winds from radiosonde measurements at Singapore (updated from Naujokat, 1986) by applying the method of Giorgetta and Bengtsson (1999). Hereafter, comparisons between the two model setups are referred to as CTL (control run) for the free-running model of HOM11, and QBO for the QBO-nudged simulation. For details on the host model and the aerosol dynamics scheme we refer the reader to HOM11 - in the following only the basic features needed to understand the experimental setup are described.

The model was integrated in T42 truncation, using an associated grid with a horizontal resolution of about $2.8^{\circ} \times 2.8^{\circ}$. In the vertical, 39 sigma-hybrid layers resolved the atmosphere up to $0.01 \mathrm{hPa}(\sim 80 \mathrm{~km})$ with a layer thickness increasing from about 1.5 to $2 \mathrm{~km}$ in the region of the tropical Junge layer. Around the stratopause, the layer thickness is about $3 \mathrm{~km}$, further increasing towards the model's top of atmosphere to $\sim 6.5 \mathrm{~km}$ (Giorgetta et al., 2006, their Fig. 1). The time integration interval was $15 \mathrm{~min}$. In the QBO configuration, the modelled zonal wind in the equatorial stratosphere is nudged towards the zonal wind profile observed at Singapore (see Giorgetta and Bengtsson, 1999), assuming a Gaussian latitudinal distribution of the zonal wind about the equator with a half-width increasing from $7^{\circ}$ at $70 \mathrm{hPa}$ to $10^{\circ}$ at $10 \mathrm{hPa}$. The nudging rate is $1 /(10$ days $)$ between $70 \mathrm{hPa}$ and $10 \mathrm{hPa}$ and between $10^{\circ} \mathrm{N}$ and $10^{\circ} \mathrm{S}$. Poleward of $10^{\circ}$ latitude the nudging rate is linearly reduced to zero at $20^{\circ}$ latitude. Outside of this region the zonal wind remains unaffected by the nudging scheme.

To ensure that the model's interannual variability is unaffected by the prescribed boundary conditions, we applied perpetual monthly climatologies of AMIP2 sea surface temperatures and sea ice concentrations as lower boundary conditions. Natural and anthropogenic sulfur emissions were taken from the AeroCom database (scenario B) and represent year 2000 conditions (Dentener et al., 2006).

In the microphysics scheme SAM2 (HOM11), aerosols are resolved throughout the atmosphere in 35 logarithmically spaced bins that range from $1 \mathrm{~nm}$ to $2.6 \mu \mathrm{m}$ in radius. For the sake of computational efficiency aerosols are assumed to be composed of a binary $\mathrm{H}_{2} \mathrm{O}-\mathrm{H}_{2} \mathrm{SO}_{4}$ mixture, which is a reasonable assumption under stratospheric conditions (e.g. Hamill et al., 1997). Microphysical processes considered are binary homogeneous nucleation (BHN; Vehkamäki et al., 2002), condensation and evaporation of water and sulfuric acid, as well as Brownian coagulation and gravitational sedimentation. In the troposphere, aerosol washout processes and surface deposition are treated as in Stier et al. (2005). Aerosols are advected segment-wise employing a semi-Lagrangian advection scheme (Lin and Rood, 1996) in terms of their mixing ratio relative to the mass of sulfur (S) incorporated in the droplets.

Similar to HOM11, the model applies an offline sulfur chemistry scheme, using prescribed monthly and zonal mean oxidant fields of $\mathrm{OH}, \mathrm{O}_{3}, \mathrm{NO}_{2}, \mathrm{H}_{2} \mathrm{O}_{2}$ from a climatology of 
the MOZART2 CTM (Horowitz et al., 2003). Similarly, OCS mixing ratios are prescribed based on a climatology from the MESSy CCM (Jöckel et al., 2005). The aerosol radiative effects follow the ECHAM5 standard approach and rely on emissivities obtained from the Tanre et al. climatology (see Roeckner et al., 2003). Interactions between aerosols and the cycles that form and maintain high-altitude clouds (cirrus and polar stratospheric clouds) have not been considered.

The model was run over 17 years, from January 1990 to December 2006. Only the last 11 years were analysed (19962006). The preceding 6 years of simulation are influenced by the spin-up of the model from the aerosol initialisation. In a technical note, Hommel (2008) showed that the modelled aerosol layer reached a steady state within that time. As of year 6, no further impact from the initialisation was detectable for any of the diagnosed aerosol parameters.

\subsection{Observational aerosol data}

For comparison, we use the aerosol surface area density (SAD) data set compiled for the WMO/SPARC Chemistry Climate Model Initiative (CCMI; http://www.pa.op.dlr.de/ CCMI; Eyring et al., 2013). This data set provides consistent aerosol forcings for the troposphere and stratosphere up to $39.5 \mathrm{~km}(\sim 3 \mathrm{hPa})$. For the stratospheric background period between 1996 and 2006, this gridded and gap-filled data set combines observations from the satellite instruments ERBS/SAGE II (1996-May 2005) and Calipso/CALIOP (June 2005-December 2006). Aerosol surface area densities were derived from SAGE II (v7) size distribution fits to measured aerosol extinction coefficients in four wavelengths as described in Arfeuille et al. (2013). This method takes the composition of aerosol droplets (weight percentage) into account, as determined by stratospheric temperature and water content of the ECMWF ERA-Interim reanalysis. CALIOP SAD were obtained from a conversion of the measured aerosol backscatter into extinction coefficients at $532 \mathrm{~nm}$ wavelength and a subsequent fit of uni-modal lognormal distributions based on SAGE II extinction correlations (B. P. Luo, ETH, personal communication, July 2013).

In relation to the SADs of the predecessor initiative CCMVal (Chemistry-Climate Model Validation Activity) forcing data set (http://www.pa.op.dlr.de/CCMVal/Forcings/ CCMVal_Forcings_WMO2010.html), the newer data provide a much better representation of aerosols in the postPinatubo stratospheric background period. Beyond 2004 CCMVal SADs were represented as recurring $5 \mathrm{yr}$-averages from 1998 to 2002, that erase any information about the QBO-Junge layer relationship in the equatorial stratosphere from the data and largely impact the derivation of anomalies from the long-term average.

A comparison to other data sets and gridded climatologies of aerosol size properties is not possible at this point, because those either cover a few years of the post-Pinatubo stratospheric background only (Bauman et al., 2003a, b; Wurl et al., 2010) or contain too many gaps (SPARC/ASAP, 2006; Wurl et al., 2010), which makes a statistically meaningful calculation of residual anomalies impossible.

We also compare to the MIPAS $\mathrm{SO}_{2}$ climatology of Höpfner et al. (2013), providing a so far unprecedented record of near-global observations of this aerosol precursor gas in the lower stratosphere. The time series contains gridded (18 10-degree latitude bins between $85^{\circ} \mathrm{N}$ and $85^{\circ} \mathrm{S}$, 36 level) monthly mean zonal means between July 2002 and April 2012, ranging in the vertical from 15 to $45 \mathrm{~km}$. Here, we analysed data up to $40 \mathrm{~km}$, and averaged meridionally between $5^{\circ} \mathrm{N}$ and $5^{\circ} \mathrm{S}$. For a meaningful comparison to our model, we interpolated MIPAS data to pressure levels according to the ICAO standard atmosphere. Note that the data set contains about $17 \%$ missing data (monthly mean zonal means on the analysed levels), which may affect the calculation of robust QBO signatures. All of the missing values appear before October 2006, and hence overlap with the time series from our model, ending in December 2006. To provide statistically significant QBO signatures, we therefore decided to analyse the entire MIPAS time series, even though the time frames do not coincide. It should also be emphasised that the Höpfner et al. (2013) climatology inherently contains the signatures of direct volcanic injections and from volcanic material which is rapidly uplifted from the troposphere into the LS (discussed in Bourassa et al., 2012; Vernier et al., 2011, 2013). Such a volcanic influence on the Junge layer is, as mentioned above, not considered in our model simulation. For the sake of simplicity we refer the reader to Höpfner et al. (2013), describing the retrieval method and discussing the quality of the retrieved $\mathrm{SO}_{2}$ profiles in comparison to e.g. the ATMOS and ACE-FTS profiles. Höpfner et al. (2013) also provide a regression analysis to determine the different signatures of natural forcings.

\subsection{Meteorology}

The model's ability to adequately reproduce the QBO through the nudging procedure is assessed by comparison to the ECMWF ERA-Interim reanalysis. Figure 1 compares the temporal development of the ERA-Interim zonal mean zonal wind at the equator from 1996 to 2006 (Fig. 1a) to the two model configurations (Fig. 1b, c). Through QBO-nudging the temporal behaviour of alternating zonal mean zonal winds in the model applied in this study is well reproduced (Fig. 1b), whereas in the free-running model (CTL) easterly winds prevail in the lower tropical stratosphere throughout the year (Fig. 1c). In the middle stratosphere, this easterly zonal wind regime is only being influenced by moderately strong westerlies $\left(<10 \mathrm{~m} \mathrm{~s}^{-1}\right)$ of the semi-annual oscillation (SAO) in the mesosphere and upper stratosphere. The westerlies are able to penetrate down to the $30 \mathrm{hPa}$ pressure level. In the nudged model, also the onset of the descent of the QBO above $10 \mathrm{hPa}$ is adequately reproduced, although in this region no nudging was performed. 


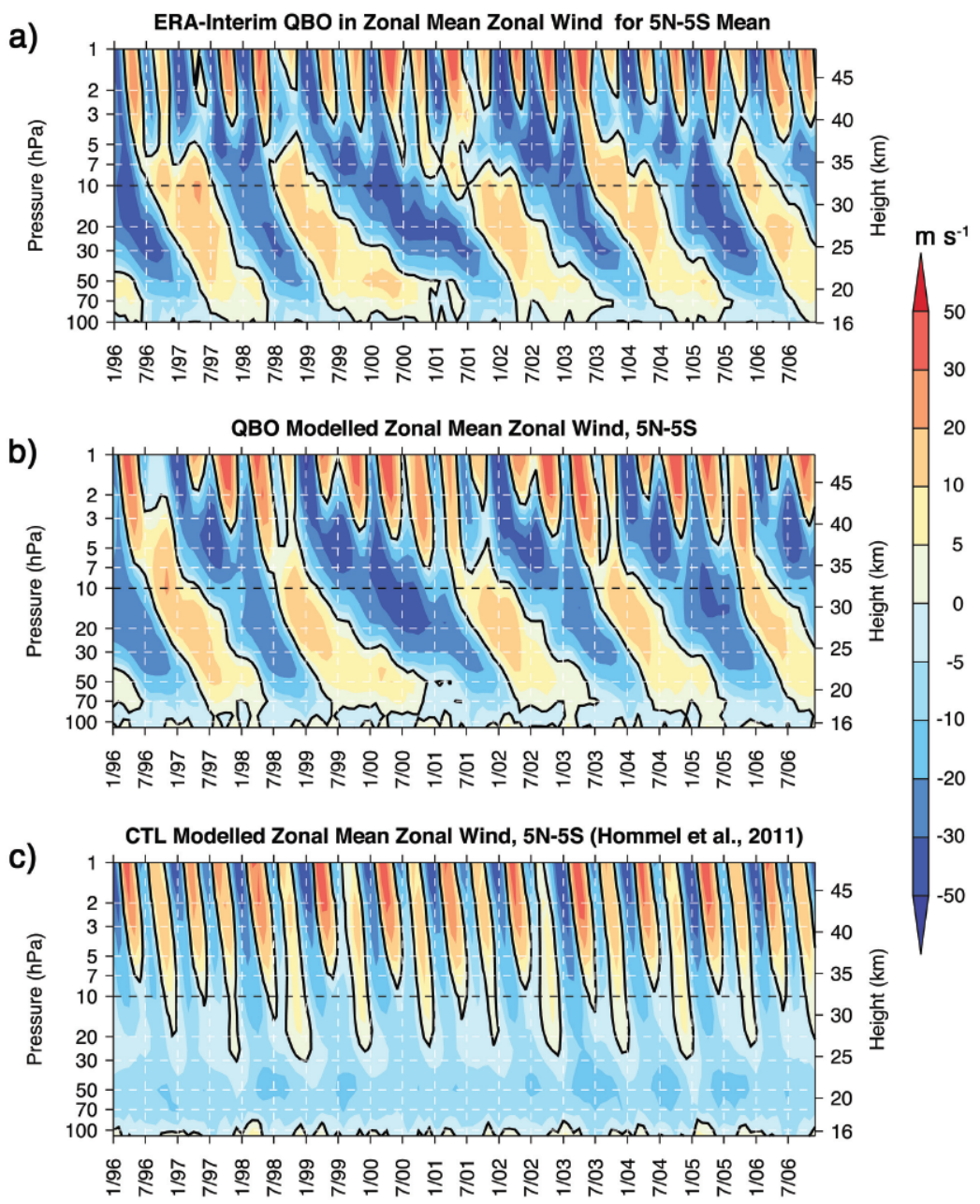

Figure 1. Temporal evolution of the monthly zonal mean zonal wind in the equatorial lower stratosphere between $5^{\circ} \mathrm{N}$ and $5^{\circ} \mathrm{S}$ for the years 1996-2006 in the (a) ECMWF ERA-Interim reanalysis and MAECHAM5-SAM2 simulations (b) with QBO-nudging and (c) in the control experiment (CTL) of Hommel et al. (2011). Reddish colours represent westerlies, blueish easterlies. Black contours highlights the month and altitude of wind transition.

Figure 2 shows associated temperature anomalies in the equatorial stratosphere that are imposed by the QBO to maintain the thermal wind balance. The QBO signature is expressed in this figure as a residual anomaly, composited relative to the time of wind shear onset at $18 \mathrm{hPa}$ (reanalysis at $20 \mathrm{hPa}$ ). The reanalysis (Fig. 2a) is 3 to $4 \mathrm{~K}$ colder around $10 \mathrm{hPa}$ during times of easterly shear and $2 \mathrm{~K}$ warmer during westerly shear between 50 and $30 \mathrm{hPa}$ than the QBO-nudged model (Fig. 2b). The model shows somewhat stronger anomalies above $10 \mathrm{hPa}$. As the climatologies of the equatorial zonal winds differ between the QBO and CTL experiments, also the temperature profiles differ (Fig. 2c). In the QBO simulation the QBO easterlies and westerlies dominate in the upper and lower stratosphere. This causes a vertical shear in the time mean that results in $\sim 1 \mathrm{~K}$ lower temperatures in the middle stratosphere and $\sim 1-2 \mathrm{~K}$ higher temperatures above the tropopause and below the stratopause, compared to the CTL simulation with a very weak wind shear in the climatological mean. Thus, in the time mean the CTL simulation has colder tropical tropopause layer (TTL) conditions than the more realistic QBO simulation with an imposed QBO. This also affects the mean tropical upwelling that is reduced by approximately one-half between $70 \mathrm{hPa}$ and $50 \mathrm{hPa}$ in the nudged model, and improves the representation of the water vapour tape recorder (Giorgetta et al., 2006).

From Fig. 1 it is obvious that only the model which represents the QBO realistically describes the variability in the equatorial stratosphere. This may have implications for thermodynamic properties of aerosols in this region and for the processes that form and maintain the aerosol layer. 
a)

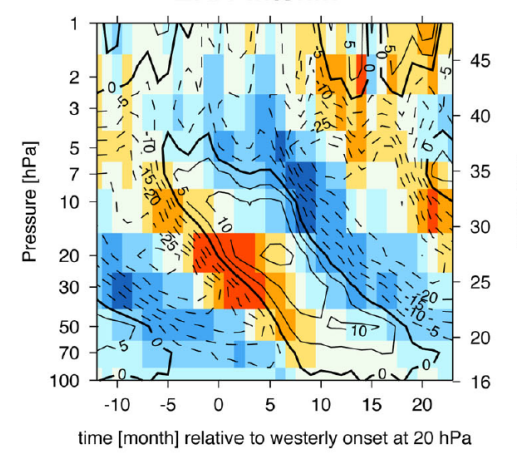

b)

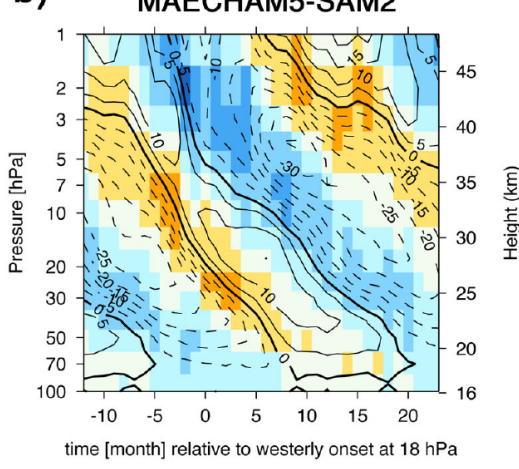

c)

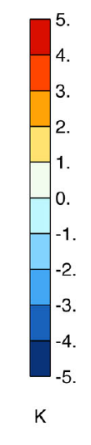

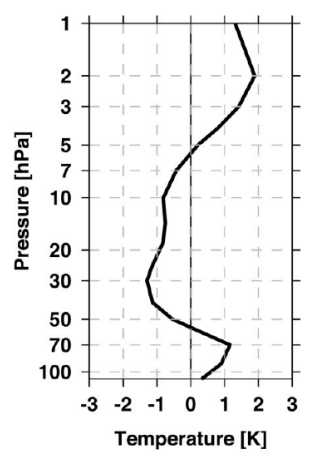

Figure 2. Residual temperature anomalies induced by the QBO in (a) the ERA-Interim reanalysis and (b) the QBO-nudged MAECHAM5SAM2 simulation between $5^{\circ} \mathrm{N}$ and $5^{\circ} \mathrm{S}$. Composited for the years 1996-2006 relative to the onset of residual westerlies at $20 \mathrm{hPa}$ and $18 \mathrm{hPa}$, respectively. Black contours denote the residual zonal mean zonal wind, where dashed lines represent easterlies. Contour interval is $5 \mathrm{~m} \mathrm{~s}^{-1}$. The difference between the climatological averaged temperature profiles of the QBO-nudged simulation and the control experiment $(\mathrm{QBO}-\mathrm{CTL})$ is shown in (c).

\section{Results and discussion}

Observational evidence that the QBO affects the stratospheric aerosol layer came from aerosol extinction measurements in the early years of systematically monitoring the stratosphere from space (e.g. Trepte and Hitchman, 1992; Grant et al., 1996). In an aerosol-coupled chemistry climate model simulation, Brühl et al. (2012) reproduced the temporal development of the tropical aerosol mixing ratio that has been inferred from SAGE II extinction measurements. But their time-slice experiment was conducted for 33 months during a period of low volcanic activity in the stratosphere between January 1999 and September 2002, that only covers a single QBO cycle. In the following, the influence of the QBO on the modelled aerosol mixing ratio is examined and their influence on other parameters describing the aerosol population in the stratosphere are investigated. Conclusively, QBO signals in precursors are examined and implications for aerosol formation and growth are given.

\subsection{Aerosol mixing ratio}

\subsubsection{Temporal evolution}

The configuration of the model in HOM11 do not allow consideration of the QBO effects on stratospheric trace constituents. Therefore, in the HOM11 study, the Junge layer behaves almost statically, in the tropics only being influenced by temperature variations in the TTL and wind alterations related to the semi-annual oscillation (SAO) in the mesosphere and upper stratosphere (Fig. 3a; see also Giorgetta et al., 2006). Figure $3 \mathrm{~b}$ shows the strong variability in the temporal evolution of the modelled aerosol mixing ratio in the equatorial lower stratosphere of the QBO-nudged experiment.
Without a QBO, anomalies in the aerosol mixing ratio, relative to the climatological mean annual cycle, appear like the tape recorder signal (not shown) in tropical stratospheric water vapour (Mote et al., 1996). Zonal winds of the SAO modulate the maximum vertical extent of the layer by $1-3 \mathrm{~km}$, but do not interfere much with the annual cycle below $\sim 14 \mathrm{hPa}$. The layer is thicker in the SAO easterly shear - the mechanisms are the same as for the QBO, and are discussed in the following.

In contrast to the CTL simulation, the interannual variability of the tropical aerosol layer in the QBO-nudged experiment is much stronger and depends on the strength and direction of the zonal winds in the equatorial stratosphere. The QBO directly influences the vertical extent of the layer and modulates the peak aerosol mixing ratio in the tropical stratospheric reservoir (TSR; Trepte and Hitchman, 1992) by about $5 \%$, relative to the CTL simulation, with larger values seen during times of maximum easterly wind acceleration. The difference in the variability of the modelled aerosol mixing ratio at the equator is also expressed in the profiles of the inferred peak-to-peak amplitudes of the annual cycles and the QBO (Fig. 4). In the upper tail of the aerosol layer, i.e. around $10 \mathrm{hPa}$, the annual cycle is approximately one-third weaker in the QBO-nudged simulation than in the model without a QBO. In contrast, the seasonality in the lower regions of the aerosol layer is approximately $25 \%$ stronger in the QBOnudged model due to the more realistic upwelling above the TTL (Giorgetta et al., 2006). The weaker seasonality around the upper tail of the layer results from the much weaker interference of the SAO with the lower stratosphere in the QBOnudged simulation, as described above.

The peak-to-peak amplitude of the QBO maximises at the $7 \mathrm{hPa}$ pressure level and is there about twice as strong as the annual oscillation at $10 \mathrm{hPa}$. Between 70 and $14 \mathrm{hPa}$, where the largest aerosol mixing ratio is found, both modulations 
are relatively weak compared to their magnitudes around the lower and the upper tail of the layer. Between 70 and $\sim 30 \mathrm{hPa}$ the amplitude of the QBO is up to twice as strong as the annual cycle, suggesting larger aerosol dynamical effects in the region than in the CTL simulation, as we will discuss in the following.

The characteristic patterns of upward and downward motion of the tropical Junge layer that have been inferred from the time series of equatorial aerosol mixing ratios in the QBO-nudged simulation (Fig. 3b) result from a superposition of advection by the extratropically driven BrewerDobson circulation (BDC), the meridional circulation imposed by the QBO (also known as the secondary meridional circulation, SMC, or residual circulation of the QBO), and the annual cycle in the tropopause temperature (see the reviews of e.g. Holton et al., 1995; Baldwin et al., 2001; Fueglistaler et al., 2009). The thermal wind relationship requires that westerly zonal wind shear is balanced by warm anomalies (e.g. Andrews et al., 1987). This causes a descent of equatorial air relative to the tropical upwelling that is associated with the BDC. Consequently, easterly zonal wind shear is balanced by cold anomalies and induced relative ascent. The associated meridional circulation is characterised by anticorrelated upward (downward) motion in the extratropics at levels of QBO westerly (easterly) shear, and meridional convergence (divergence) in the QBO westerly (easterly) jet. Hence, advective effects of the secondary circulation of the QBO on the QBO jets contributes to narrower (in latitude) and deeper westerly jets compared to wider and shallower easterly jets. The secondary circulation determines the meridional extent of the TSR which is confined by the subtropical mixing barriers (e.g. Trepte and Hitchman, 1992; Grant et al., 1996). During the time of maximum easterly zonal wind acceleration it expands meridionally (horizontal divergence) and appears compacted in the vertical (vertical convergence). The opposite is the case during times of maximum westerly zonal wind acceleration: the tropical stratosphere is narrowed in the horizontal and stretched in the vertical. Those structures are easily inferable from concentration gradients of stratospheric trace constituents. A respective model goes back to the works of Plumb and Bell (1982); for TSR aerosol it was first reported by Trepte and Hitchman (1992) based on aerosol extinction measurements from SAGE I and II instruments in the periods 19791981 and 1984-1991, when the volcanic aerosol load of the stratosphere was relatively low. Underlying mechanisms were later examined in detail by Choi et al. (1998) and Choi et al. (2002) from HALOE observations of aerosol extinction, ozone and other trace gases.

These relationships are responsible for the characteristic temporal evolution of the simulated Junge layer in the tropics. To better illustrate the net effect of the QBO on the simulated aerosol mixing ratio (Fig. 5a) we have composited the time series (Fig. 3b) similarly to the temperature anomaly composites (Fig. 3), i.e. relative to the onset of the westerly zonal wind shear at $18 \mathrm{hPa}$. The corresponding deviation in geometric altitude of the $0.25 \mathrm{ppbm}$ isopleths is shown in Fig. $5 \mathrm{~b}$ as well as the approximated thickness of the Junge layer, expressed as vertical extent between the $0.25 \mathrm{ppbm}$ isopleths above and below the modelled maximum aerosol mixing ratio.

As seen in Figs. 5 and 3b, the largest vertical expansion of the Junge layer slightly lags behind the occurrence of strongest QBO westerlies, when the layer thickness can reach $8 \mathrm{~km}$. The largest reduction in the vertical extent lags behind strongest QBO easterlies and reaches $2 \mathrm{~km}$ at minimum. The vertical spread of the layer is accompanied with an increase in its top height (expressed by mixing ratios $<0.08 \mathrm{ppbm}$ ), varying between $\sim 10 \mathrm{hPa}$ during times of the onset of westerly winds and $\sim 6 \mathrm{hPa}$ in the aftermath of the easterly QBO shear (note that the $0.25 \mathrm{ppbm}$ isopleth of Fig. $5 \mathrm{~b}$ is distinctly below the layer's upper lid). In contrast to the composite plots, where local effects may be smeared by the somewhat irregular period of the QBO, from the time series of Fig. $3 \mathrm{~b}$ one can better infer that the increase in the layer's top height is stronger at lower altitudes where the layer is denser, i.e. between 20 and $10 \mathrm{hPa}$. For instance, the gradient of the $0.25 \mathrm{ppbm}$ isopleth above the mixing ratio maximum is steeper after the strongest QBO westerlies. In the composites, however, this gradient appears smoother. In the lower regions of the layer the lofting of aerosols outweigh displacements at its upper lid. Bottom displacements are of the order of $3-5 \mathrm{~km}$, whereas the layer's top drifts no more than $2-3 \mathrm{~km}$.

It is clearly shown in both the time series (Fig. 3b) and the composite (Fig. 5a) that after the layer reaches its largest vertical expansion, the model predicts that the entire layer descends under the influence of descending easterly zonal winds. As mentioned above, this descent is of the order of $2-3 \mathrm{~km}$ around the onset of the westerly wind shear around the $15 \mathrm{hPa}$ pressure level. This settling is accompanied by the above-mentioned horizontal divergence of the TSR, which shifts the subtropical mixing barriers a few degrees poleward (Grant et al., 1996; Neu et al., 2003). The net change of this variation, that is the difference in the layer thickness due to the QBO, is at least $5 \mathrm{~km}$ (Fig. 5b).

Since this spatio-temporal structure of TSR aerosols is intrinsically linked to circulation patterns superimposed by the QBO in the tropical upwelling branch of the BDC, the model predicts that the SMC stabilises the Junge layer at higher altitudes, where in the QBO-free model of HOM11 aerosols are no longer thermodynamically stable. Mechanisms that act in particular on the top lid of the layer are discussed in greater detail in Sect. 3.4.

\subsubsection{QBO induces anomalies in the tropical mixing ratio}

To gain further insight into QBO effects on the dynamics of aerosols in the tropical lower stratosphere, in the follow- 


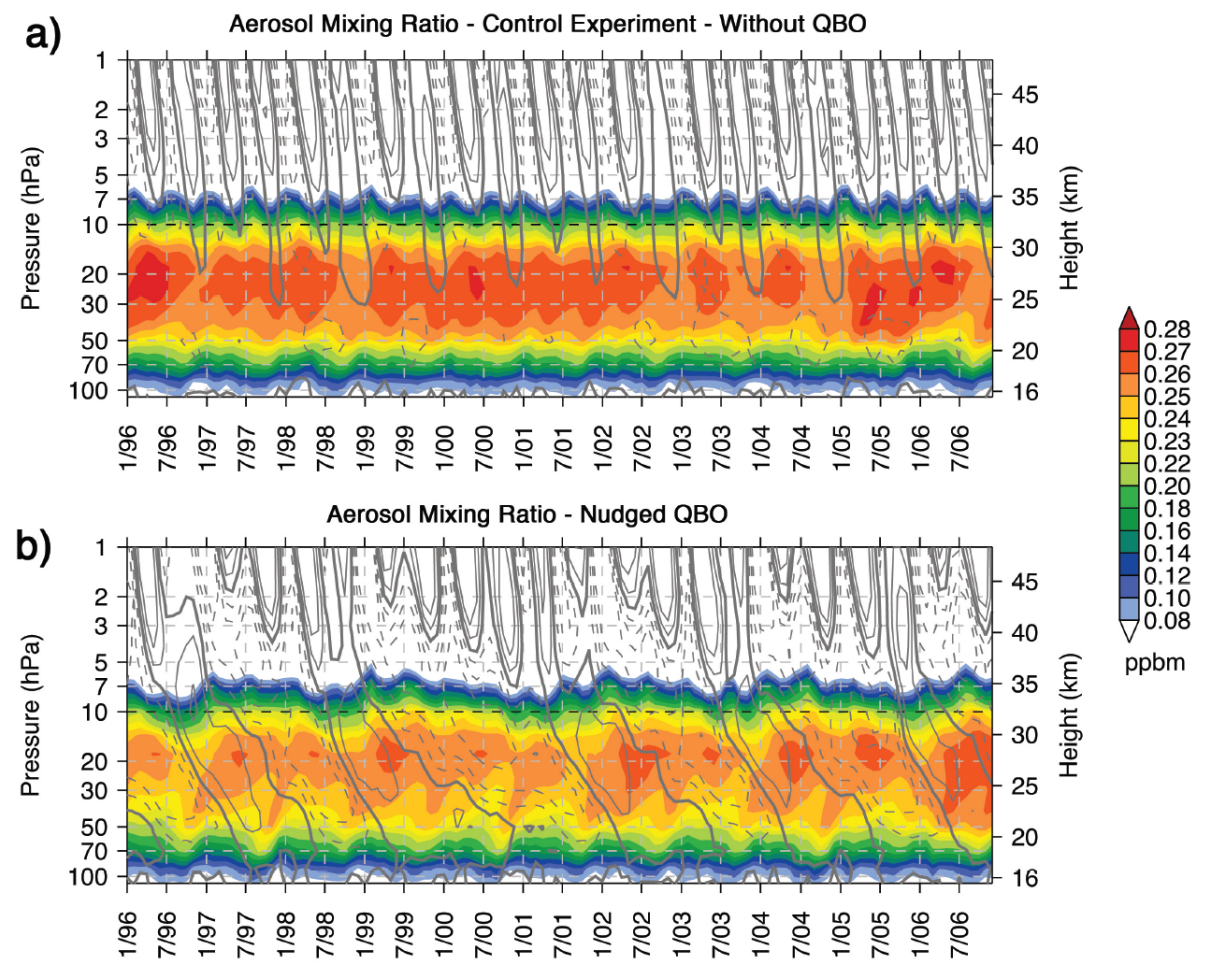

Figure 3. Temporal evolution of the monthly mean zonal mean aerosol mass mixing ratio $\left(\times 10^{9} \mathrm{~kg}_{(\mathrm{S})} \mathrm{kg}^{-1}\right)$ in (a) the CTL simulation of Hommel et al. (2011) and (b) the QBO-nudged model between $5^{\circ} \mathrm{N}$ and $5^{\circ} \mathrm{S}$ for the years 1996-2006. Grey contours denote the zonal wind as in Fig. 1, where dashed lines represent easterlies.

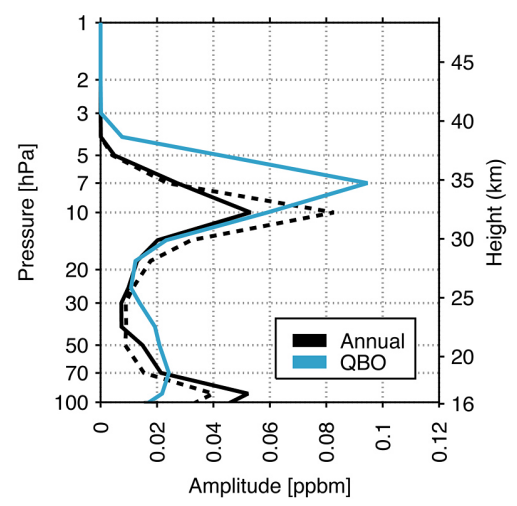

Figure 4. Comparison of the approximate peak-to-peak amplitudes of the annual cycle and the QBO in the simulated aerosol mixing ratio of the QBO-nudged model (straight lines), and the of the control simulation CTL without a QBO (dashed line). All data averaged between $5^{\circ} \mathrm{N}$ and $5^{\circ} \mathrm{S}$ for the years 1996-2006. The peak-to-peak amplitude of the QBO is estimated following Baldwin and Gray (2005). The peak-to-peak amplitude of the annual variation refers to difference between the maximum and the minimum of the calculated climatological mean annual cycle.

ing we discuss simulated anomalies induced by the QBO in aerosol mixing ratio and other $\mathrm{LS}$ aerosol properties. All data are zonal means and have been averaged between $5^{\circ} \mathrm{N}$ and $5^{\circ} \mathrm{S}$. Profile data are climatological means of the analysed period. Composites of residual QBO anomalies, relative to the time of the onset of westerly zonal mean zonal wind at $18 \mathrm{hPa}$, were obtained from monthly means.

Figure 6a shows the climatological averaged aerosol mixing ratio profile, which is the time-average of the modelled temporal evolution of the equatorial aerosol mixing ratio (Fig. 3). The corresponding residual anomalies, induced by the QBO, are shown in Fig. 6b. The QBO signal is significant on the $95 \%$ confidence level (according to the Student's $t$-test) at all pressure levels where the mixing ratio exceeds $0.1 \mathrm{hPa}$. At the upper lid of the Junge layer, also QBO modulations of mixing ratios $<0.08 \mathrm{ppbm}$ are significant.

The QBO induces the largest anomalies where the vertical gradient in the mixing ratio is strong (Fig. 6b). Hence, strongest anomalies are found in the region where sulfate droplets evaporate, that is at the upper lid of the Junge layer, between 10 and $7 \mathrm{hPa}$. During QBO easterly phase, the bulk mixing ratio increases in this region by about $60 \%$. In the QBO westerly shear and during the QBO westerly phase a decrease relative to the mean annual cycle of $60-90 \%$ is found. In contrast, around $20 \mathrm{hPa}$, where the bulk mixing ratio is largest, and below, in regions where the mixing ratio gradient is positive, only very moderate $\mathrm{QBO}$ modulations of less than $\pm 5 \%$ are found. 
a) Composited Aerosol Mixing Ratio

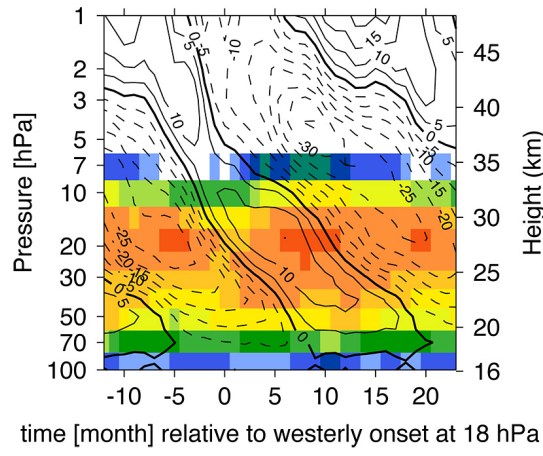

b)

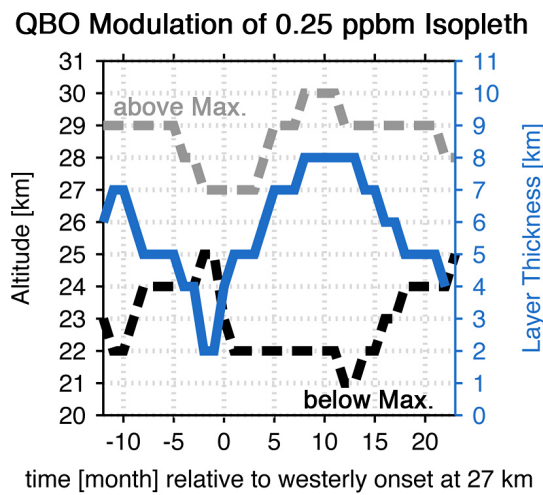

Figure 5. (a) Composite of the simulated aerosol mixing ratio in the QBO-nudged model relative to the onset of residual westerlies at $18 \mathrm{hPa}$ corresponding to the time series Fig. 3b. Data are averaged between $5^{\circ} \mathrm{N}$ and $5^{\circ} \mathrm{S}$ for the years $1996-2006$. (b) Composite of the height variation of the $0.25 \mathrm{ppbm}$ isopleth above (grey) and below (black) the mixing ratio maximum from panel (a). The blue line is the corresponding vertical extend between those two isopleths as an approximate measure of the QBO modulation of the Junge layer thickness with time. Geometric altitudes in (b) have been inferred from the model's sigma-hybrid levels, whereas in (a) the approximate altitude of the pressure levels, based on the ICAO standard atmosphere, are shown.

A similar QBO signature has been found in the literature for tropical stratospheric ozone (see review in Baldwin et al., 2001). From observations and models it is known that QBO-induced ozone anomalies have phase reversals around $10 \mathrm{hPa}$, corresponding to the altitude of maximum ozone mixing ratio in the equatorial stratosphere (Hasebe, 1994; Butchart et al., 2003). The phase reversal results from QBO modulations in the vertical advection as discussed above. QBO anomalies in our modelled aerosol mixing ratio exhibit such a phase reversal along isopleths of descending zonal mean zonal winds around the $20 \mathrm{hPa}$ pressure level. This is the level where the aerosol mixing ratio is largest. Negative anomalies occur in the westerly shear, where the vertical mixing ratio gradient is negative (above $20 \mathrm{hPa}$ ), and positive anomalies where the gradient is positive (below $20 \mathrm{hPa}$ ). Ozone anomalies at the equator are reported to be of the order of 3 to $15 \%$ (e.g. Butchart et al., 2003), hence are of similar strength as the QBO-related aerosol variability in regions where the mixing ratio gradient is positive. Above, in the evaporation region, the aerosol $\mathrm{QBO}$ is somewhat stronger with relative modulations exceeding $50 \%$. This implies that QBO modulations in the aerosol transport alone cannot explain this behaviour. Therefore, it is reasonable to assume that QBO modulates microphysical processes as well, in particular the process of aerosol evaporation in higher altitudes (Sect. 3.4). Despite the similarities between the QBOs in ozone and aerosol in the tropical lower stratosphere, there is a distinct difference between them: the thermodynamic limitation of the stability of liquid-phase aerosols in the LS imposes a characteristic oscillating temporal behaviour on the upper edge of the tropical Junge layer (clearly shown in the mixing ratio time series Fig. 3b), which is not known from the ozone layer in the tropical stratosphere. Implications for the size of aerosols and processes that maintain them are discussed in the following sections.

\subsection{Integrated aerosol size parameters}

\subsubsection{Surface area density}

Integrated aerosol parameters inferred from observed aerosol extinction coefficients at specific wavelength are fraught with uncertainties when the fraction of small particles significantly contributes to an aerosol size distribution (Dubovik et al., 2000; Thomason et al., 2008). SPARC/ASAP (2006) emphasised that this effect is particularly relevant when the aerosol load of the stratosphere is low. HOM11 showed that a systematic bias between observations and the CTL simulation arises in integrated aerosol size quantities when $\mathrm{H}_{2} \mathrm{SO}_{4}$ condensation dominates the growth of LS aerosols. Thus, in comparisons between integrated aerosol size quantities from models and remote sensing, particular attention should be paid to the systematic bias that is due to the fine-mode fraction of aerosol populations.

Also in our simulation, the SAD depends on the size range of the integration. This can be seen by comparing the climatological mean profiles (Fig. 7a, c). When aerosols smaller than $50 \mathrm{~nm}$ are not taken into account to mimic a satellite sensor (panel c), the profile has a positive gradient below $70 \mathrm{hPa}$. It shows $10 \%$ lower values at this particular pressure level, relative to the profile taking all simulated aerosol sizes into account (panel a). Above $70 \mathrm{hPa}$, both profiles decrease with height, which results from persistent changes in the size spectrum of the particles: at lower levels, larger particles are more abundant than in the upper layers. This is because the sedimentation velocity increases with height and at higher altitudes, the saturation vapour pressure of $\mathrm{H}_{2} \mathrm{SO}_{4}$ at the surface of an aerosol droplet increases so that the parti- 

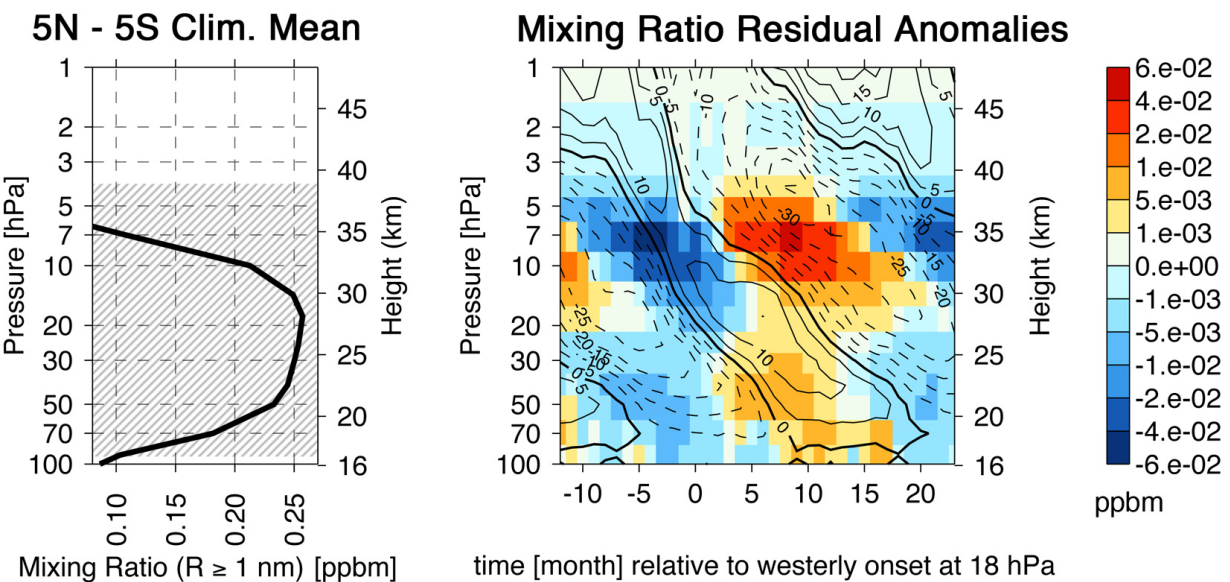

time [month] relative to westerly onset at $18 \mathrm{hPa}$

Figure 6. (a) Climatological mean profile of the modelled aerosol mass mixing ratio between $5^{\circ} \mathrm{N}$ and $5^{\circ} \mathrm{S}$ for the period $1996-2006$. (b) Composite of QBO-induced residual anomalies in the modelled aerosol mass mixing ratio with respect to the time of onset of westerly zonal mean zonal wind at $18 \mathrm{hPa}$. As in Fig. 2b, black contours denote the residual zonal wind. Dashed lines represent easterlies, contour interval is $5 \mathrm{~m} \mathrm{~s}^{-1}$. Grey shades in (a) denote levels where the QBO signal exceeds the $95 \%$ significance level, according to the standard Student's $t$-test.

cles evaporate more quickly. Both mechanisms shape the size distribution at higher altitudes towards the fine mode.

Compared to the CTL simulation (HOM11), with a less variable tropical Junge layer, the QBO-nudged version shows $6 \%$ lower SADs throughout the year between $80 \mathrm{hPa}$ and $20 \mathrm{hPa}$. In contrast, directly above the TTL SADs are larger by $4-6 \%$ in the QBO model and up to $30 \%$ larger above the $10 \mathrm{hPa}$ pressure level. This is the region where evaporation is strong.

QBO signatures of the two SAD integrals also differ (Fig. $7 \mathrm{~b}$ and d) - in particular below $20 \mathrm{hPa}$, where the effect of the smaller aerosol arises which would not be seen by the satellite-sensor. Although the anomaly pattern are different, their relative strength is of the order of $\pm 5 \%$ in both cases. Considering small aerosols in the calculation of the SAD increases the statistical significance of the inferred anomalies between 50 and $30 \mathrm{hPa}$. This also points to the important role of smaller particles for the SAD determination.

Relative QBO modulations of the SAD are much stronger above $20 \mathrm{hPa}$. They may exceed $\pm 100 \%$ although absolute values in this region are more than 1 order of magnitude smaller than in regions of the layer further below. Those large modulations can be explained by QBO modulations in the reversible mass transfer of sulfuric acid vapour. In regions where warm (cold) anomalies are induced by the QBO in westerly (easterly) shear, the QBO fosters evaporation (condensation) and the SAD will be smaller (larger). In Sect. 3.4 we examine this relationship in more detail. Similar to the region below $20 \mathrm{hPa}$, here the relative strength of the QBO modulations is approximately similar in the two SAD integrals.

In contrast to the mixing ratio, statistical significance is limited to certain regions of the modelled SAD. The change in SAD from all sizes is significant at the $95 \%$ confidence level, according to Student's $t$-test, between 50-18 and 10$4 \mathrm{hPa}$, and directly above the TTL below the $90 \mathrm{hPa}$ pressure level. QBO-related anomalies of the $\geq 50 \mathrm{~nm}$ SAD are significant only where aerosols evaporate, i.e. $20-18$ and $10-4 \mathrm{hPa}$.

The climatological mean surface area density profiles derived from satellite observations are substantially smaller compared to the model as shown in Fig. 8a (below $20 \mathrm{hPa}$ relative differences exceed a factor of 2). The data sets have been provided by the WMO/SPARC initiatives CCMI and CCMVal for the use in CCMs. HOM11 found similar differences between the modelled SAD of the CTL configuration and SAGE II SAD climatologies from Bauman et al. (2003a, b) and Wurl et al. (2010). HOM11 emphasise that their comparison is in agreement with SPARC/ASAP (2006), pointing out significantly positively biased SADs (by a factor of 2-10) in the tropical LS for the majority of models that participated in an intercomparison against the SAGE II v6.2 SAD.

Below the $30 \mathrm{hPa}$ pressure level, the climatological mean tropical profile of the CCMI SAD forcing data set is about $30 \%$ smaller than in the CCMVal SAD forcing data set. Above $\sim 15 \mathrm{hPa}$ the CCMI SAD forcing is distinctly larger with values above $0.3 \mu \mathrm{m}^{2} \mathrm{~cm}^{-3}$, whereas, in contrast, the CCMVal SAD forcing tends to be zero. The latter indeed agrees better to our QBO and CTL simulations, where above $15 \mathrm{hPa}$ the aerosols begin to evaporate and shrink in size, which imposes a net loss in mass and also in the aerosol's number density.

Although the climatological mean values of the CCMI SAD forcing data set at the equator are smaller than in our model simulations, observed QBO-induced anomalies (Fig. 8b) agree to a certain extent with our model predictions, in particular above $20 \mathrm{hPa}$ during the QBO east phase. Be- 
a)

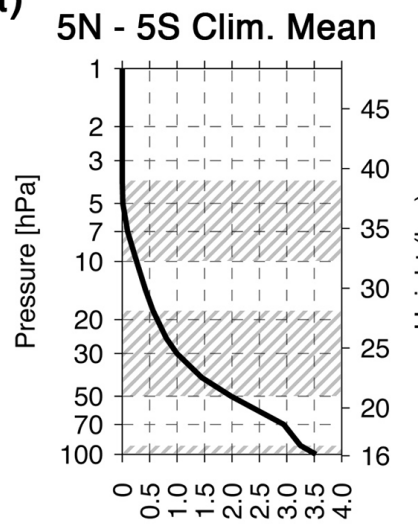

Surface Area $(R \geq 1 \mathrm{~nm}) \quad[u \mathrm{~m} 2 \mathrm{~cm}-3\rceil$ b)

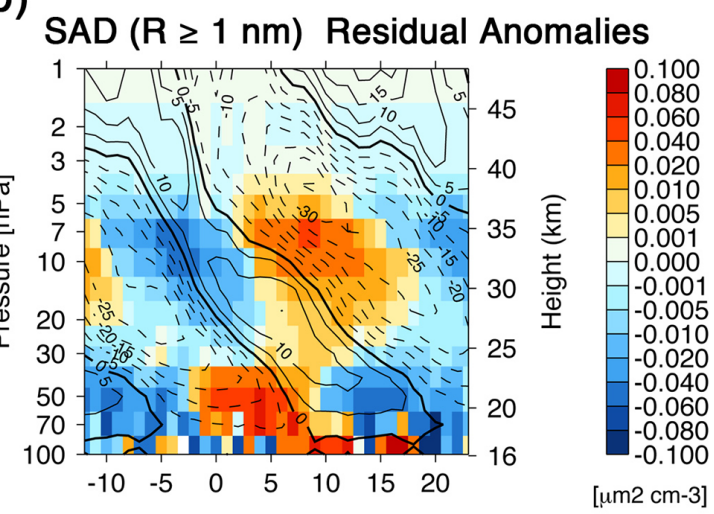

time [month] relative to westerly onset at $18 \mathrm{hPa}$ c)

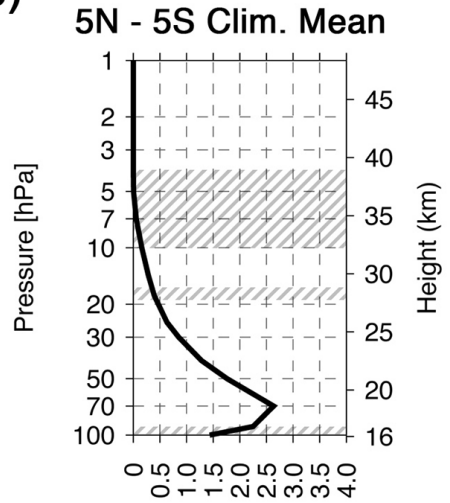

Surface Area $(R \geq 50 \mathrm{~nm}) \quad[\mu \mathrm{m} 2 \mathrm{~cm}-3]$ d)

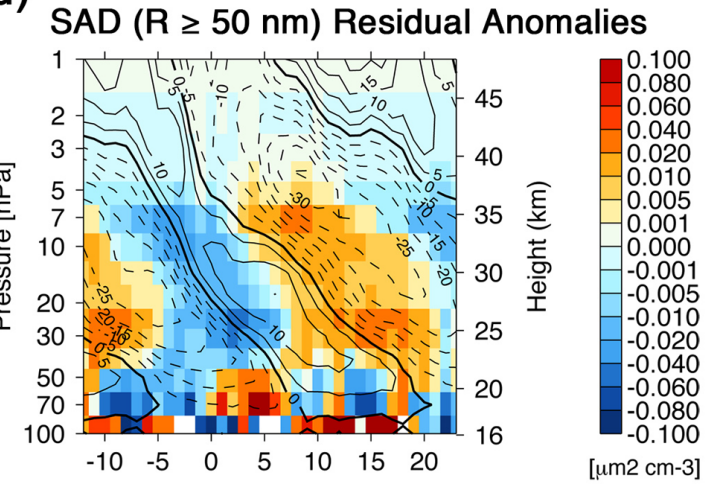

time [month] relative to westerly onset at $18 \mathrm{hPa}$

Figure 7. As in Fig. 6, except for residual anomalies in the modelled aerosol surface area density (SAD). Data in the upper panels have been inferred from the entire modelled size distribution $(1 \mathrm{~nm} \leq R<2.6 \mu \mathrm{m})$. In the lower panels the aerosol size range has been adapted to the detectability of space-borne remote sensors $(50 \mathrm{~nm} \leq R<2.6 \mu \mathrm{m})$.
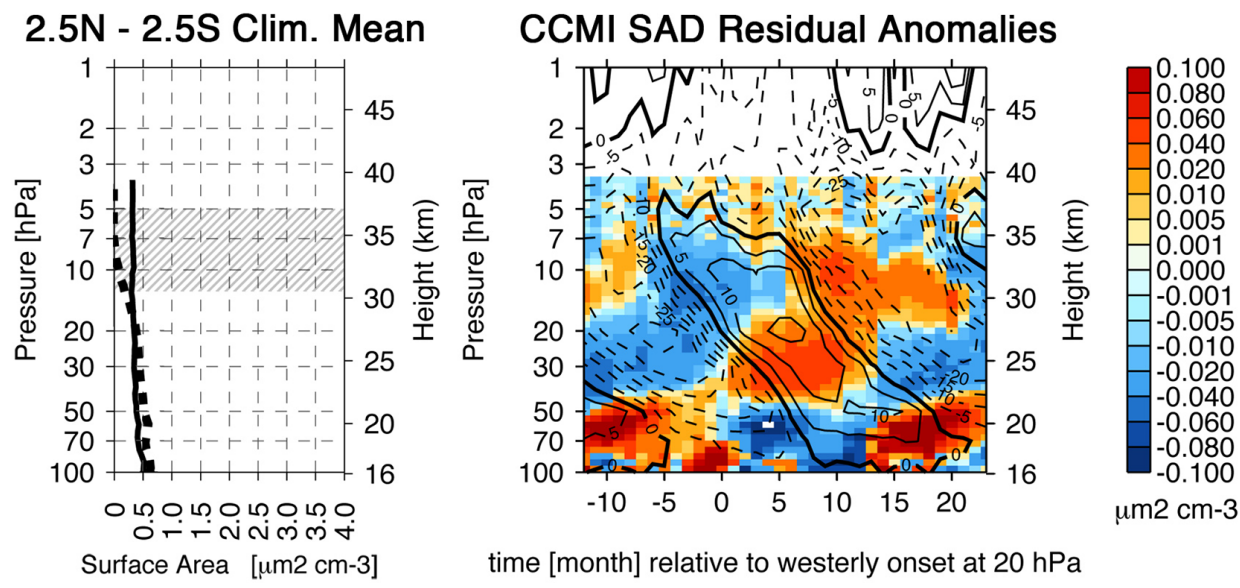

Figure 8. As in Fig. 6, except for the SAD climatology between $2.5^{\circ} \mathrm{N}$ and $2.5^{\circ} \mathrm{S}$ of the SPARC CCMI initiative, inferred from spaceborne SAGE II and CALIOP observations. The profile in (a) is complemented by the climatological averaged SAD of the SPARC CCMVal initiative. The overlaid zonal wind in (b) is obtained from the ECMWF ERA-Interim climatology as in Fig. 2a. 
tween the TTL and $20 \mathrm{hPa}$ inferred anomalies are up to $60 \%$ larger than in the model. This is very clearly reflected at pressure levels where the QBO westerly zonal wind is strongest, i.e. between 40 and $20 \mathrm{hPa}$. Below $40 \mathrm{hPa}$, anomalies of opposite sign are found in CCMI compared to the model, in particular where westerly zonal winds prevail. This may reflect the release of volcanic material into the lower tropical stratosphere, which is not considered in the simulations. Several moderate volcanic eruptions occurred in the later years of the analysed period (tropical volcano eruptions of Ruang occurred in late 2002, Manam in January 2005, Soufrière Hills in May 2006 and Tavurvur in October 2006) and are suspected to have dispensed sufficient amounts of precursors in the tropical LS, that quickly formed new aerosols (Vernier et al., 2011; Neely et al., 2013). The subsequent formation, dispersion and lofting of volcanic aerosol may have an effect on the inferred QBO signatures from CCMI. This relationship is complex, and needs further investigation, also taking other observations and data sets, as well as more specific model simulations into account.

Inferred QBO signatures in the CCMI SAD are statistically significant at the $95 \%$ confidence level between 14 and $5 \mathrm{hPa}$ only. This is approximately the same altitude range where the $R \geq 50 \mathrm{~nm}$ SAD integral of the simulation is significant. Note that, in contrast to the simulation, where we used the $t$-test, for observational data sets (CCMI and MIPAS) we employed the $F$ statistics to compare the amplitude of the QBO spectral peaks to the red noise spectrum (e.g. Gilman et al., 1963; von Storch and Zwiers, 1999).

\subsubsection{Effective radius}

The aerosol effective radius $\left(R_{\text {eff }}\right)$ is another key parameter widely used in the determination of upper troposphere and lower stratosphere (UTLS) aerosol climate effects (e.g. Grainger et al., 1995). Although negatively biased to the SAGE II climatologies of Bauman et al. (2003a, b) and Wurl et al. (2010) as well as in situ observations of the balloonborne optical particle counter of the University Of Wyoming (Deshler et al., 2003), in the control experiment without a QBO, the model-predicted $R_{\text {eff }}$ lies within the uncertainty range of the measurements (HOM11). Compared to the CTL experiment, the climatological mean tropical $R_{\text {eff }}$ profile in the QBO experiment (Fig. 9a) shows 1-2.5\% smaller values, except in the lowest regions, between the TTL and $70 \mathrm{hPa}$, where it is about $2 \%$ larger.

In Fig. 9b QBO-induced $R_{\text {eff }}$ anomalies are shown for aerosols larger than $50 \mathrm{~nm}$ in radius to ensure comparability with the particle sizes seen by remote sensing instruments. Although the patterns of QBO anomalies indicate strong modulations in $R_{\text {eff }}$ except in the region between 20 and $10 \mathrm{hPa}$, their relative strength is large only above $10 \mathrm{hPa}$, where the size of evaporating aerosols rapidly decreases with increasing altitude. Here, QBO-related anomalies reach $60 \%$ and are approximately in-phase with anomalies in the mixing ratio (Fig. 6b) and anomalies in the SAD (Fig. 7b). Below $20 \mathrm{hPa}$, QBO-induced modulations are smaller than $\pm 5 \%$, which is weaker than in the SAD. Statistical significance at the $95 \%$ confidence level is reached throughout the equatorial belt, except between $10-4 \mathrm{hPa}$.

No QBO signature would be seen in $R_{\text {eff }}$ if the QBO affects the aerosol volume distribution and surface distribution in an equal measure. This is quite interesting as HOM11 pointed out that most of the differences between the model $R_{\text {eff }}$ and observational estimates can be assigned to invariable moments of the modelled aerosol populations (the relative position between volume and surface distribution in the model does not vary much in the stratosphere). In reality, the different moments seem to be much more variable (bottom panel of Fig. 9 in HOM11), and QBO nudging apparently helps to improve the model results.

\subsection{Number density}

In previous sections, $\mathrm{QBO}$ effects on integrated aerosol quantities were examined. In the following we further investigate how the QBO affects the size of aerosols in the tropical LS by an analysis of anomalies induced in specific ranges of their size distribution. Therefore, the modelled size distribution is partitioned into four size ranges, equivalent to the four modes, which are commonly used to define an aerosol distribution (e.g. Seinfeld and Pandis, 2006). In this respect, nucleation mode aerosols refer to particles with radii smaller than $0.005 \mu \mathrm{m}$. The Aitken mode is defined as the range between $0.005 \mu \mathrm{m}$ and below $0.05 \mu \mathrm{m}$ and the accumulation mode between $0.05 \mu \mathrm{m}$ and below $0.5 \mu \mathrm{m}$. The coarse mode considers aerosols with radii equal to or larger than $0.5 \mu \mathrm{m}$.

Figure 10 shows that QBO modulations are different in the four modes. This was implicitly expressed also in Fig. 7 by the small differences in the anomalies in SAD for the two integration ranges (whole spectrum and aerosols larger than $50 \mathrm{~nm}$ ). In contrast to SAD anomalies, relative QBO effects in aerosol number densities are much stronger.

As seen from the nucleation mode number density profile (Fig. 10a), the model suggests that binary homogeneous nucleation (BHN) occurs in the tropical LS. Below $50 \mathrm{hPa}$, several hundred nucleation mode aerosols are found per $\mathrm{cm}^{-3}$ in the simulation. Above $50 \mathrm{hPa}$, their number density rapidly decreases and is almost 3 orders of magnitude lower around $20 \mathrm{hPa}$ and above. Since the BHN parameterisation depends on the ambient temperature and water vapour content, it is not surprising that the QBO may influence the particle formation process. This is indicated by the strong QBO modulations $( \pm 50 \%)$ we find in nucleation mode number densities between 50-30 hPa (Fig. 10b). At the higher levels, the increasing stratospheric temperature and the decreasing moisture content suppress BHN. However, small fluctuations are even seen above $30 \mathrm{hPa}$, indicating that either rapid vertical transport of freshly formed nuclei is imposing those signatures or even in the central and upper regions of the 

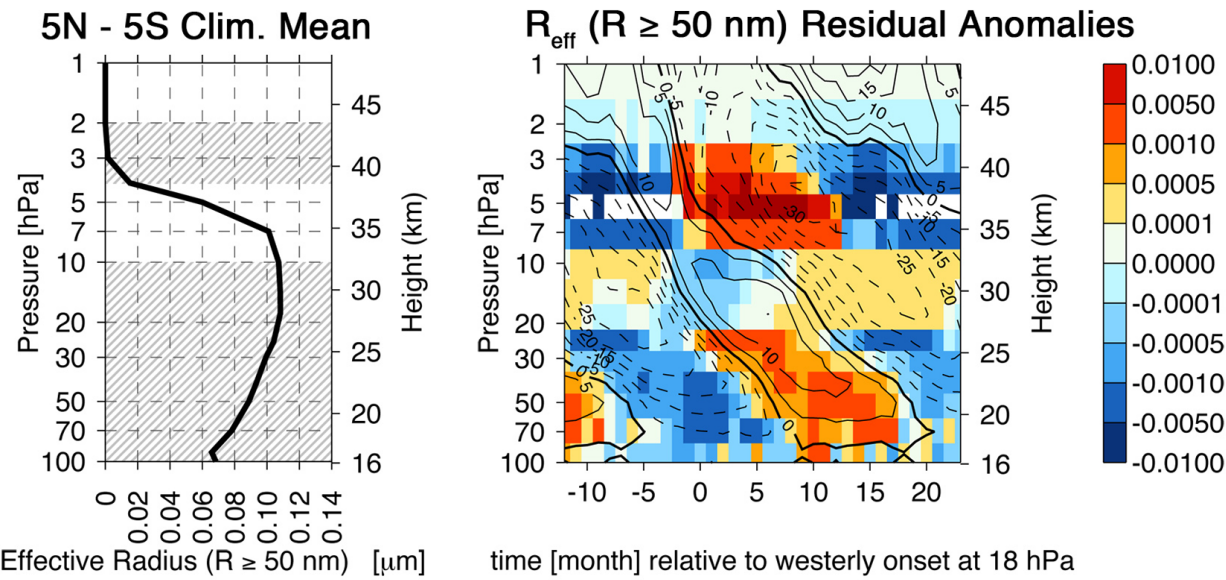

Figure 9. As in Fig. 6, except for the modelled effective radius of aerosols with $R \geq 50 \mathrm{~nm}$.

Junge layer nucleation is triggered by QBO imposed temperature fluctuations on relatively short timescales. We will further examine those relationships in Sect. 3.4. Anomalies at $70 \mathrm{hPa}$ are of similar strength but shifted in phase to anomalies above. Below that level, only irregular patterns have been inferred which do not correlate with the dissipating QBO signal nor with the inferred nucleation rate anomalies (compare Fig. 11b). The origin of these artefacts and their relation to seasonal variations in the TTL have not yet been understood and should be investigated in more detail in future studies. Statistical significance of the signatures is confined to levels between 70 and $40 \mathrm{hPa}$. As a caveat it should be mentioned that the nucleation process of aerosols, in particular in the LS, is poorly understood. Therefore, the above relationships strongly rely on the assumptions we made in modelling the process and for the composition and size of nucleation mode aerosols.

Strong positive modulations, i.e. increased number densities, are seen in the larger three modes of the size distribution (Fig. 10d, f, h) during easterly QBO phases and above regions where the largest bulk mixing ratios are found (30-20 hPa). Anomalies in the coarse-mode number density (Fig. 10h) appear somewhat irregularly in the lowest levels above the TTL. Here, the QBO signal interferes with effects imposed by the annual cycle in the tropical tropopause, which has no definite synchronisation with the QBO phase (Baldwin et al., 2001). Above $70 \mathrm{hPa}$, coarse-mode number density anomalies are positive during the time when easterly zonal wind prevails and may reach $\pm 100 \%$ in the evaporation region due to the low abundance of aerosol coarse-mode particles there, as seen from the climatological mean profile (Fig. 10g). Statistical significance is indicated only between 30 and $14 \mathrm{hPa}$ - that is, where such relatively heavy particles are quickly being removed by sedimentation.

Alterations in the accumulation mode number density (Fig. 10c) are mainly confined to regions where the droplets evaporate and get smaller. The relative strength of the anoma- lies increases almost linearly from $\pm 5 \%$ at $20 \mathrm{hPa}$ to about $\pm 100 \%$ around $3 \mathrm{hPa}$. In contrast to the coarse mode, from the climatological mean profile (Fig. 10e) it is obvious that at the higher altitudes accumulation mode particles are still relatively abundant, although at least 1 order of magnitude less than further below, where the bulk mixing ratio is largest (Fig. 6a). In the latter region and all the way down to the TTL, relative modulations are as low as $\pm 5 \%$. Statistical significance is indicated in three regions of the equatorial LS that is, in the lowest analysed levels between 100 and $90 \mathrm{hPa}$, in central regions of the layer between 40 and $18 \mathrm{hPa}$ as well as between 10 and $4 \mathrm{hPa}$.

In the tropical LS, the Aitken mode aerosol concentration is largest just above the TTL, and rapidly decreases with increasing height (Fig. 10c). Collisional scavenging (coagulation) is responsible for the concentration decrease in the lower region of the layer, up to $30 \mathrm{hPa}$, while evaporation is a sink for both aerosol mass and number density above $20 \mathrm{hPa}$. Relative QBO modulations in the Aitken mode number density are quite strong throughout the entire tropical Junge layer. They are not statistically significant in a layer between $25-10 \mathrm{hPa}$, which is where the climatological mean profile has almost no gradient. QBO signatures of $\pm 20 \%$ are found between 50 and $30 \mathrm{hPa}$ and reach $\pm 100 \%$ in the evaporation region. That is in contrast to the previously discussed modes, the mixing ratio and the SAD, where strong relative modulations are confined to the upper regions of the layer (above $30 \mathrm{hPa}$ ). In addition, also the characteristic patterns of positive/negative anomalies and their phase reversal in the vertical make this particular QBO effect exceptional in comparison to the other analysed QBO effects on tropical LS aerosols. This result clearly indicates that QBO effects on aerosol processes in the tropical LS interact highly nonlinearly with each other. 
a)

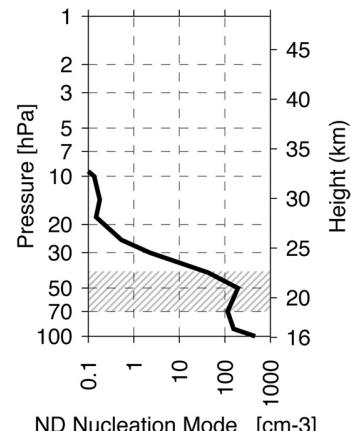

ND Nucleation Mode [cm-3]

c)

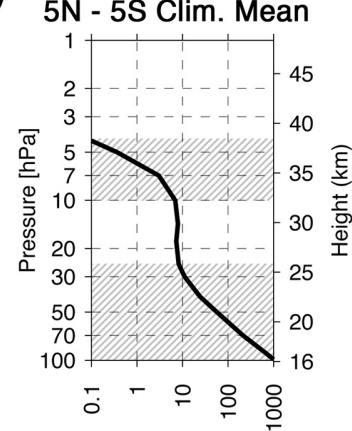

ND Aitken Mode [cm-3]

\section{e)}

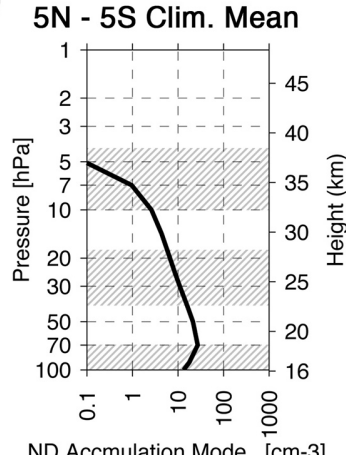

b) Nucleation Mode Residual Anomalies

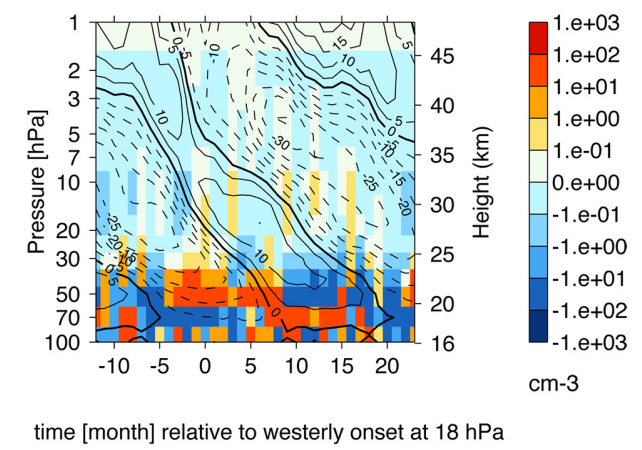

d)

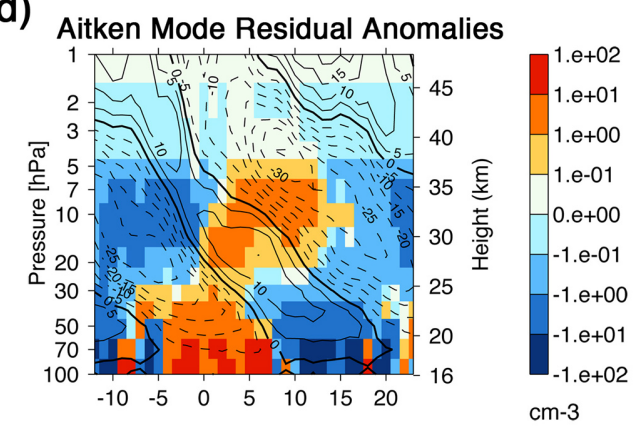

time [month] relative to westerly onset at $18 \mathrm{hPa}$

\section{f) Accumulation Mode Residual Anomalies}

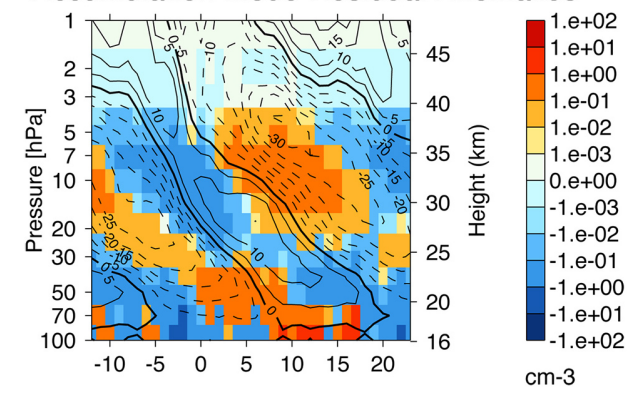

time [month] relative to westerly onset at $18 \mathrm{hPa}$ g)

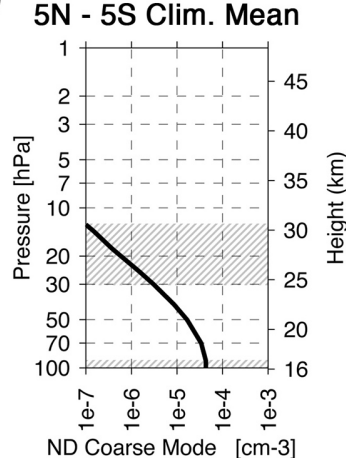

h)

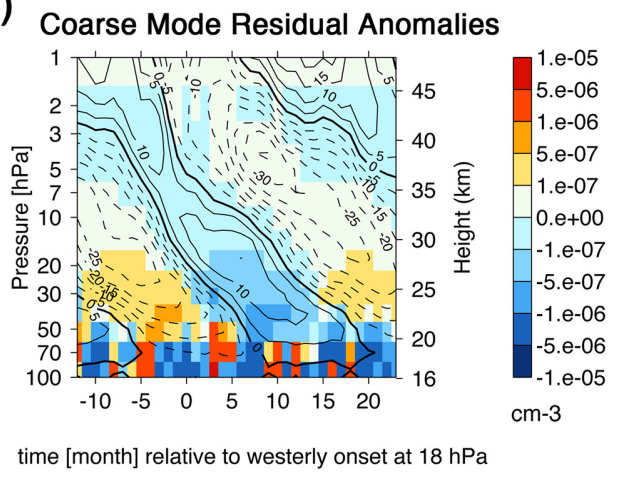

Figure 10. As in Fig. 6, except for modelled number densities as integrals over specified modes: (a) and (b) nucleation mode $(R<0.005 \mu \mathrm{m})$, (c) and (d) Aitken mode $(0.005 \mu \mathrm{m} \leq R<0.05 \mu \mathrm{m})$, (e) and (f) accumulation mode $(0.05 \mu \mathrm{m} \leq R<0.5 \mu \mathrm{m})$, and (g) and (h) coarse mode $(R \geq 0.5 \mu \mathrm{m})$. 


\subsection{Microphysical processes}

To reveal the mechanisms responsible for the QBO effects discussed above, we further examine how the QBO affects microphysical processes of transferring sulfur mass between the gas and the aerosol, i.e. nucleation and condensation/evaporation. Principally, the strength of the processes depends on the thermodynamic state of the stratosphere. The saturation of $\mathrm{H}_{2} \mathrm{SO}_{4}$ and $\mathrm{H}_{2} \mathrm{O}$, which depends on temperature and vapour concentrations, determines the rate of formation of new aerosol as well as their growth and loss through reversible mass transfer between the gas and the liquid phase. Coagulation and sedimentation are other important microphysical processes which shape size distributions (e.g. Jacobson, 2005) and limit the vertical extent of the aerosol layer (e.g. Kasten, 1968; Hamill et al., 1977, 1997). Since both processes have not been diagnosed from the model in a way that will allow a consistent determination of their QBO signatures, in the following we focus on a discussion of QBO signals in aerosol nucleation and $\mathrm{H}_{2} \mathrm{SO}_{4}$ condensation/evaporation. Nevertheless, at the end of the section we make an attempt to estimate potential QBO effects on coagulation and sedimentation, because both processes have been explicitly considered in the model system and their (non-isolated) effects presumably superimpose other analysed QBO signatures.

\subsubsection{Nucleation}

In the lower tropical stratosphere, the modelled BHN rate after Vehkamäki et al. (2002) exhibits a maximum at $50 \mathrm{hPa}$ (Fig. 11a). The climatological mean profile has a sharp negative gradient above $50 \mathrm{hPa}$, and is not different from the CTL run (HOM11). The pattern of QBO-induced anomalies in the aerosol nucleation rate (Fig. 11b) correlates well with the QBO signature in the nucleation mode number density (Fig. 10b). The cold anomaly in QBO easterly shear zones imposes a 5-10\% amplification of the BHN rate around the $50 \mathrm{hPa}$ pressure level. Although this is not a large number, the respective increase in the nucleation mode number density can be as large as $+50 \%$ during times when QBO easterlies are strongest. During that time the layer approaches its lowest vertical expansion, so that the disproportional modulation in the number density of nuclei may arise from dampening the advective aerosol lofting or from QBO-induced downward transport (relative to the climatological mean state). At $30 \mathrm{hPa}$ and above, no significant impact of the QBO on the $\mathrm{BHN}$ is found, so that respective signatures seen in the nucleation mode number density (Fig. 10b) may have a different origin than new particle formation. QBO effects in the lowest regions of the LS interfere with seasonal variations in the TTL, with the result that the composited QBO signatures in the BHN rate appear rather irregularly.

As discussed in Sect. 2.3, modelled QBO signatures in the tropical LS temperature show a warm bias compared to
ERA-Interim in regions where BHN occurs. Assuming other properties remain constant, colder anomalies would foster BHN (Vehkamäki et al., 2002). Therefore, it is likely that the modelled QBO signature in BHN may be underestimated, apart from uncertainties which remain for the rarely investigated process under stratospheric conditions. Statistical significance is indicated between 70 and $30 \mathrm{hPa}$, very similar to signatures in the nucleation mode number density.

\subsubsection{Condensation of $\mathrm{H}_{2} \mathrm{SO}_{4}$}

Below $50 \mathrm{hPa}$, the model indicates that the $\mathrm{H}_{2} \mathrm{SO}_{4}$ condensable source rate (in units of $\mathrm{cm}^{-3} \mathrm{~s}^{-1}$ ) is quite strong, but it decreases rapidly with height as seen from its climatological mean profile (Fig. 11c). The respective QBO signature (Fig. 11d) shows three regimes that are out of phase in the upper and lower regions of the Junge layer. Phase reversals occur around $15 \mathrm{hPa}$ and between 7 and $5 \mathrm{hPa}$. Only regions below $25 \mathrm{hPa}$ are statistically significant.

When easterly winds prevail at $50 \mathrm{hPa}$ or below, positive anomalies in the condensable source rate of the order of $5-10 \%$ are induced by the QBO. Here, QBO-induced cold anomalies in the stratospheric temperature (Fig. $2 b$ ) reduce the saturation vapour pressure of $\mathrm{H}_{2} \mathrm{SO}_{4}$ at the droplet surface that fosters condensation. Since in these regions the total aerosol number concentration is much larger than above, the aerosol provides a large surface area for condensing molecules (Fig. 7a), and is therefore a strong sink for the $\mathrm{H}_{2} \mathrm{SO}_{4}$ vapour.

However, relative QBO anomalies are much larger (about $\pm 60 \%$ ) in regions of the Junge layer where aerosols predominately release their mass into the gas phase, i.e. above $20 \mathrm{hPa}$ (Fig. 11e). This indicates that both processes occur simultaneously in the time mean, and there is no sharp transition identifiable between regions where aerosols predominantly grow or shrink. Here, above $20 \mathrm{hPa}$, the reversible mass transfer of $\mathrm{H}_{2} \mathrm{SO}_{4}$ molecules is in a cyclic balance that depends on the strong in-phase relationship between the QBO-modulated stratospheric temperature and the $\mathrm{H}_{2} \mathrm{SO}_{4}$ vapour pressure. QBO-modulated upwelling through the tropical tropopause (Gray and Chipperfield, 1990; Seol and Yamazaki, 1998) may additionally contribute to QBO signatures in $\mathrm{H}_{2} \mathrm{SO}_{4}$ condensation and are further discussed in Sect. 3.7.

In the regions of the Junge layer where the mixing ratio and the number densities of intermediate size aerosol are sufficiently large, i.e. below $10 \mathrm{hPa}$, the QBO signatures in the condensable source rate of $\mathrm{H}_{2} \mathrm{SO}_{4}$ correspond well with those in the Aitken mode number density (Fig. 10d). At certain levels they also correspond with the signatures in the number densities of the accumulation mode (between 50 and $30 \mathrm{hPa}$ ) and the coarse mode (between the TTL and $70 \mathrm{hPa}$ ). 
a)

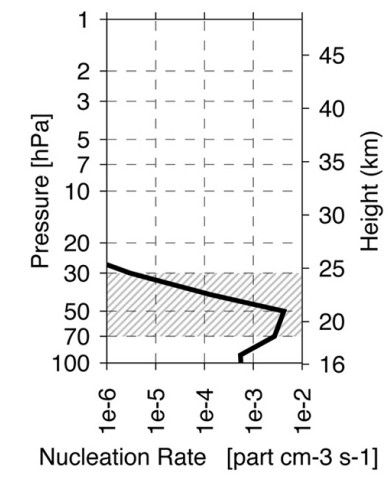

b)

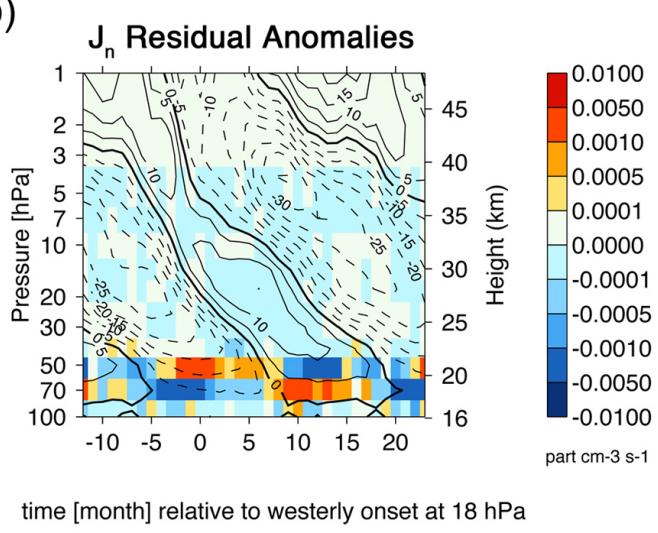

C)

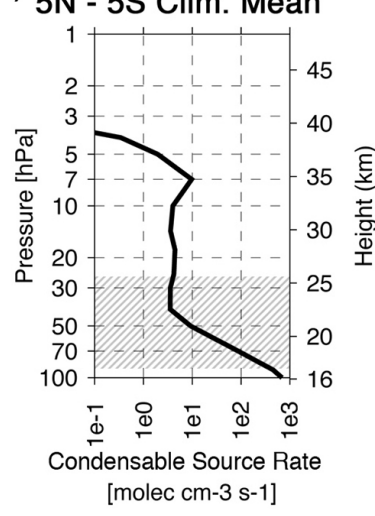

e)

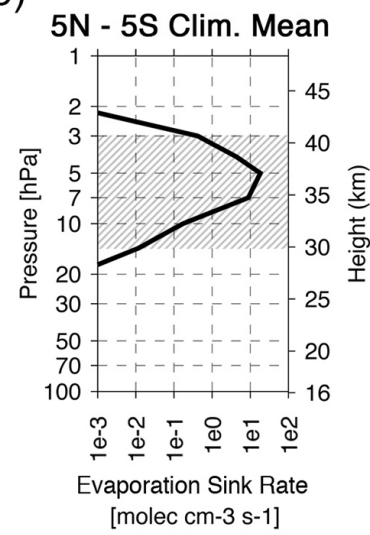

d) Condensable Source Rate

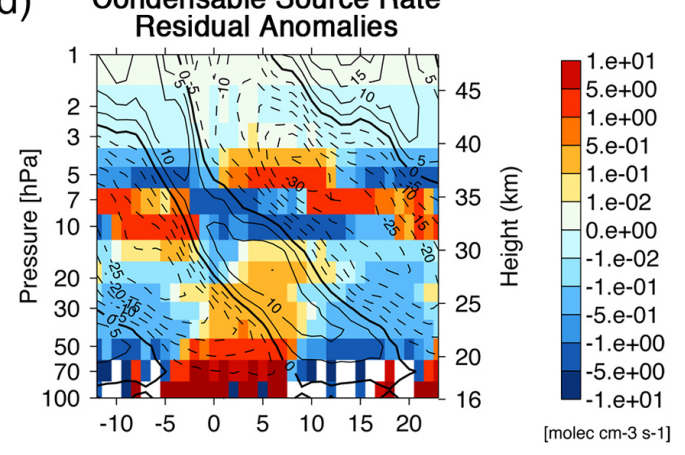

time [month] relative to westerly onset at $18 \mathrm{hPa}$

f)

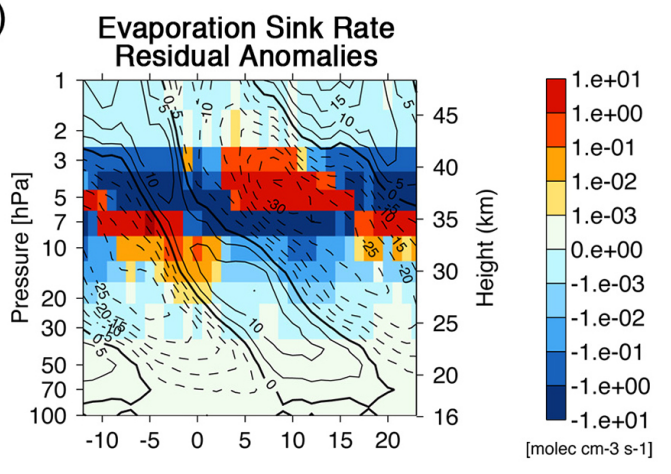

time [month] relative to westerly onset at $18 \mathrm{hPa}$

Figure 11. As in Fig. 6, except for modelled microphysical processes. The upper panel shows the binary homogeneous nucleation rate $\left(\mathrm{cm}^{-3} \mathrm{~s}^{-1}\right)$ as parameterised by Vehkamäki et al. (2002). The middle panel shows the time-averaged condensable source rate of $\mathrm{H}_{2} \mathrm{SO}_{4}$ vapour $\left(\mathrm{cm}^{-3} \mathrm{~s}^{-1}\right)$ and the bottom panel the respective counterpart, the time-averaged evaporation sink rate of $\mathrm{H}_{2} \mathrm{SO}_{4}$ molecules $\left(\mathrm{cm}^{-3} \mathrm{~s}^{-1}\right)$.

\subsubsection{Evaporation of $\mathrm{H}_{2} \mathrm{SO}_{4}$}

Above $20 \mathrm{hPa}$, the $\mathrm{H}_{2} \mathrm{SO}_{4}$ saturation vapour pressure at the surface of the droplets gets larger than the $\mathrm{H}_{2} \mathrm{SO}_{4}$ partial pressure due to the photochemical production of $\mathrm{H}_{2} \mathrm{SO}_{4}$, and aerosols evaporate quicker than at lower altitudes. The process reaches its maximum strength around 7 to $5 \mathrm{hPa}$
(Fig. 11e). Above that level, most of the sulfate mass remains in the vapour phase, so that the evaporation sink rate (in $\mathrm{cm}^{-3} \mathrm{~s}^{-1}$ ) of $\mathrm{H}_{2} \mathrm{SO}_{4}$ molecules from the aerosols into the gas phase gets weaker with height.

Due to the strong in-phase relationship between the $\mathrm{H}_{2} \mathrm{SO}_{4}$ vapour pressure and the $\mathrm{QBO}$ temperature signature, evaporation anomalies are also in phase with temperature 
anomalies imposed by the QBO. The model indicates that during the warm anomaly QBO westerly shear the process is fostered, while cold anomalies in the QBO easterly shear have a dampening effect. The modulation is of the order of $\pm 60 \%$ at the highest temperature signatures. Statistical significance is indicated between 14 and $3 \mathrm{hPa}$.

Figure $11 \mathrm{~d}$ and f imply that the two intrinsically competing processes (condensation and evaporation) appear simultaneously. This effect arises mainly from the time averaging of the data, and to a lesser extent also from zonal averaging. Nevertheless, condensation and evaporation compete on the process level in the model and are characterised by their unidirectional molecular flows either onto or away from the particles. Although equally phased anomalies may overlap partially in the residual composites, an analysis of their QBO signatures is still possible since both processes have been diagnosed from individual output channels during model integration time. We infer, indeed, a remarkable feature in the coupling of the two processes in comparison to the CTL simulation without a QBO: in the QBO-nudged simulation the balance of the $\mathrm{H}_{2} \mathrm{SO}_{4}$ mass transfer is shifted towards evaporation above $10 \mathrm{hPa}$. This is because the tropical Junge layer has a much larger variability in the QBO-nudged simulation than in the CTL simulation. In principle the process of evaporation decreases the SAD (the total number of aerosols remains either constant when they evaporate or decreases due to complete evaporation), but in the QBO experiment this effect is partly compensated by the QBO-modulated vertical advection of small aerosols. This results in a positively modulated SAD in the QBO easterly shear above $10 \mathrm{hPa}$ (Fig. 7).

It should be mentioned that compared to the ERA-Interim reanalysis, modelled QBO temperature anomalies are up to $2 \mathrm{~K}$ smaller below the $10 \mathrm{hPa}$ pressure level (Fig. 2a, b) and 1-2 K larger above $10 \mathrm{hPa}$, where evaporation occurs. Thus, in the model the net effect of QBO on the counteracting processes evaporation and condensation of $\mathrm{H}_{2} \mathrm{SO}_{4}$ may be overestimated to some degree. On the other hand, due to the large QBO-induced variations of the Junge layer's upper lid, presumably temperature-related biases in the modelled QBO interactions are more pronounced for evaporation. That is because the process ultimately determines the maximum altitude of the layer's upper lid, dependent on the saturation state and the thermodynamic stability of aerosol.

\subsubsection{Coagulation and sedimentation}

Although not diagnosed in the same manner as the $\mathrm{H}_{2} \mathrm{SO}_{4}$ mass transfer, some aspects about the interference between the QBO and the coagulation and sedimentation processes can be derived from first principles, causal relationships of the atmospheric aerosol system (e.g. Seinfeld and Pandis, 2006; Hamill et al., 1997) and our results. Both processes have been modelled together with the other three processes (nucleation, condensation, evaporation), as described above. It is important to bear in mind that coagulation is a mass conserving process, affecting the number of aerosols (predominately the smallest - a review is found e.g. in Jacobson, 2005). In contrast, sedimentation is a sink for both mass and number of aerosols (e.g. Hamill et al., 1977).

Since sedimentation is predominantly limiting the Junge layer's vertical extent (the strength of the sink increases almost linearly with altitude), mainly the aerosol layer's upper lid is supposed to be affected by QBO modulations of sedimentation. According to first principles, an Aitken mode aerosol of $10 \mathrm{~nm}$ radius settles about $0.1 \mathrm{kmmonth}^{-1}$ at $10 \mathrm{hPa}$ and an accumulation mode aerosol with $100 \mathrm{~nm}$ radius settles about 8 times faster $\left(\sim 0.8 \mathrm{~km} \mathrm{month}^{-1}\right)$. The rate approximately doubles when the aerosol is lofted by $3 \mathrm{~km}$ over 3-4 months, as indicated by our model during the QBO east phase (Fig. 5b). Note that this result already incorporates the effect of the QBO on sedimentation. Since larger aerosols are relatively abundant at $10 \mathrm{hPa}$ and above (Fig. 10e and top left panel of Fig. 13), the numbers imply an effective sedimentation sink for larger aerosols, counteracting the aerosol lofting by the QBO. This relationship can be understood as in indirect signature of the QBO on the sedimentation flux of particles from the upper region of the Junge layer. A secondorder, direct effect on the sedimentation of LS aerosols is also conceivable - that is, the imposed QBO signature on the dynamic viscosity of air, determining the falling speed of an aerosol. This modulation may occur via the $1-2 \mathrm{~K}$ modulation of the tropical stratospheric temperature in regions where the sedimentation sink is large enough to play a role. In our model we used the parameterisation of Pruppacher and Klett (1979), suggesting that a QBO signature in the dynamic viscosity of air is $\ll 1 \%$. Hence, the signal is small and presumably not distinguishable from other signals.

QBO effects on the process of aerosol coagulation may also be divided into direct and indirect effects. A potential direct QBO signature occurs via modulation of the (Brownian) diffusion coefficient of the aerosol due to the imposed temperature anomalies and the coefficient's dependence on altitude. The effect is potentially not negligible above $10 \mathrm{hPa}$ where air is less dense and the Knudsen number (ratio between the mean free path of air molecules to the aerosol size) is approximately 1 order of magnitude larger than at $100 \mathrm{hPa}$. A more distinct signature, however, seems to be plausible through indirect QBO modulations via the pathway of triggering new particle formation, as discussed above, and their subsequent coagulation. Potentially also vertical advection of nuclei contributes to this indirect QBO effect, because also the sedimentation sink of the smallest aerosol increases rapidly if they are lofted.

Further studies are needed to understand the complex and partly nonlinear relationships of these respective QBO effects that may be of particular importance when geoengineering options are investigated. 
a)

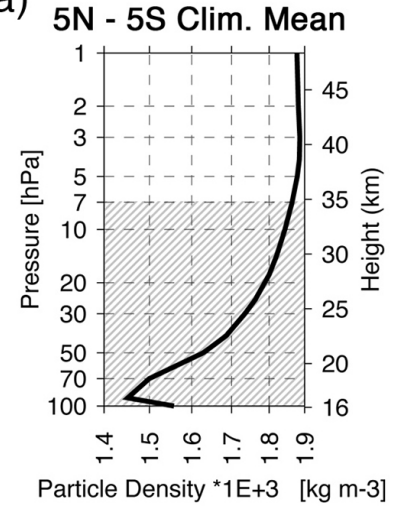

c)

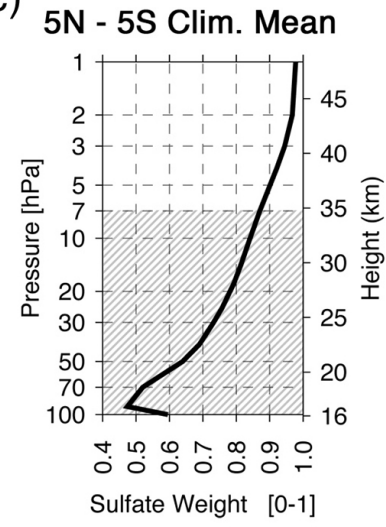

e)

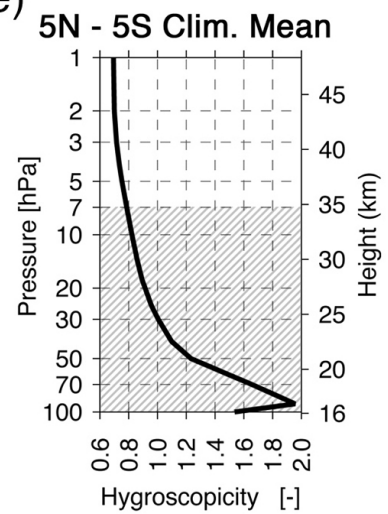

b)

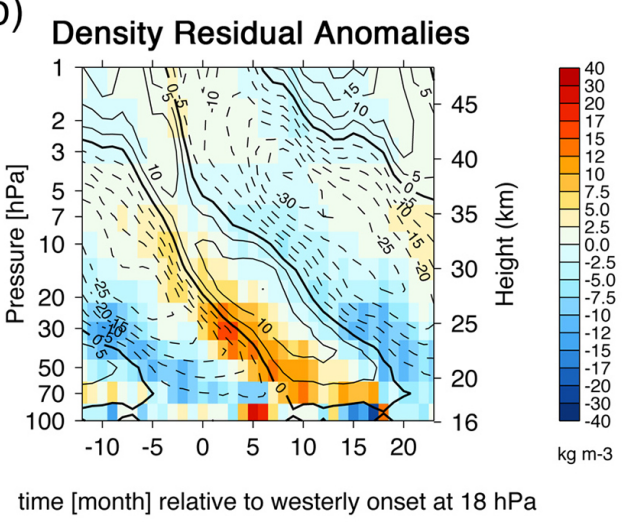

d)

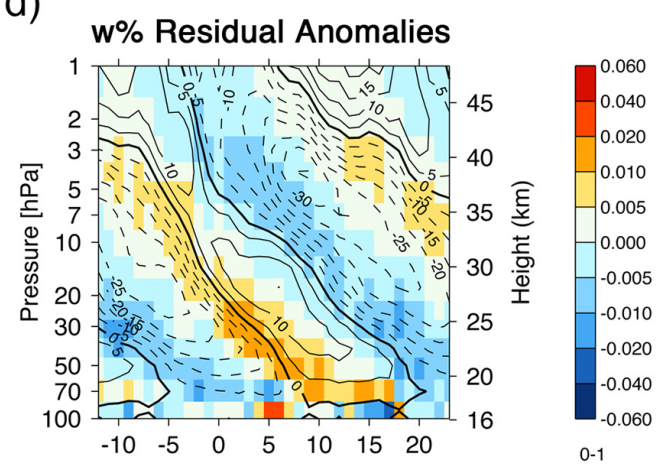

time [month] relative to westerly onset at $18 \mathrm{hPa}$

f)

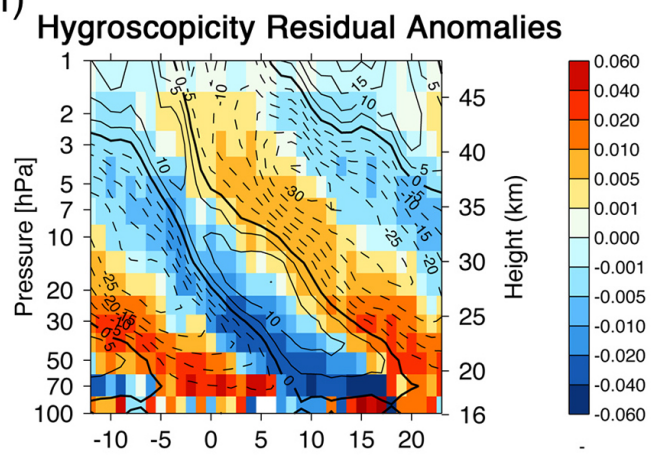

time [month] relative to westerly onset at $18 \mathrm{hPa}$

Figure 12. As in Fig. 6, except for modelled sulfate aerosol properties. The upper panel shows the density of the binary $\mathrm{H}_{2} \mathrm{SO}_{4}-\mathrm{H}_{2} \mathrm{O}$ solution, the middle panel the $\mathrm{H}_{2} \mathrm{SO}_{4}$ weight percentage, and the bottom panel the aerosol water content relative to a representative Junge layer aerosol composition (e.g. Rosen, 1971).

\subsection{Particle properties}

Aerosols in the stratosphere become more concentrated with height until the increase in the $\mathrm{H}_{2} \mathrm{SO}_{4}$ saturation vapour pressure at the surface of the droplet sets an upper limit to the thermodynamic stability of the droplets. The concentration change of the droplet solution is obvious from the climatological mean tropical profiles of the binary solution density (Fig. 12a), the sulfuric acid weight percentage of the droplets
(Fig. 12c), and their water content (Fig. 12e). The latter is expressed as the relative difference to a representative Junge layer aerosol mean state widely used in the literature (density of $1.7 \mathrm{~g} \mathrm{~cm}^{-3}$, sulfuric acid weight percentage of 0.75 ; see e.g. Rosen, 1971; Hamill et al., 1997).

Changes in the aerosol composition play an important role for understanding seasonal variations of observed aerosol optical properties (e.g. Yue et al., 1994; Hamill et al., 1997). Since equilibrium with respect to water is achieved quasi- 
instantaneously also in the relatively dry stratosphere, small variations in the water content forced by the QBO may additionally contribute to QBO signatures in the droplet composition that arise from QBO-induced temperature anomalies or advection due to the residual circulation of the QBO.

Residual QBO anomalies of the diagnosed particle properties (Fig. 12b, d, f) indeed reveal a strong analogy to QBO-induced temperature anomalies of the tropical stratosphere (Fig. 2b). Aerosols have a higher sulfuric acid weight percentage during times when positive temperature anomalies are induced during the QBO westerly shear. Although respective relative modulations almost linearly scale with the QBO temperature signal, of the order of approximately $\pm 1 \%$, this has extensive consequences for aerosol microphysics above the $20 \mathrm{hPa}$ pressure level, because it facilitates evaporation and reduces the SAD. The opposite occurs in the relatively cold QBO east shear. All QBO signatures are statistically significant up the $7 \mathrm{hPa}$ pressure level.

The analysed aerosol properties are also modulated by changes due to seasonal variations in the stratospheric temperature (e.g. Steele and Hamill, 1981; Yue et al., 1994). Since the latter are stronger above the TTL than in the middle stratosphere, seasonal variations in the aerosol properties play a particular role below the evaporation region. For instance, at $70 \mathrm{hPa}$ the sulfuric acid weight percentage and water content vary between summer and winter by about $20 \%$ (not shown), and the density of the droplet solution by $\sim 6 \%$. At $10 \mathrm{hPa}$ the variations do not exceed $1-2 \%$. Hence, below approximately $20 \mathrm{hPa}$, these variations are up to a magnitude stronger than the inferred QBO signatures. This is clearly different from the aerosol mixing ratio (Fig. 4), where only below $70 \mathrm{hPa}$ seasonal variations are (approximately two times) stronger than the QBO signal.

\subsection{Size distribution}

The QBO imprint in modelled aerosol size distributions is shown in Fig. 13 for QBO east phases, exemplarily for pressure levels of 10 and $40 \mathrm{hPa}$. Signatures in QBO west phases have an opposite sign (not shown). The upper panels depict size distributions from linear interpolations between adjacent bins in terms of number concentrations (particles $\mathrm{cm}^{-3}$ ). To better illustrate the QBO effect, the bottom panels show relative differences per bin as bar charts. The bars are colour coded by aerosol modes, as discussed in Sect. 3.3. As before, all data are monthly zonal means between $5^{\circ} \mathrm{N}$ and $5^{\circ} \mathrm{S}$. In order to provide an independent diagnostics, we sampled the data according to the sign of the QBO east phase zonal wind tendency $\mathrm{d} U_{\mathrm{EQBO}} / \mathrm{d} t$, and not according to the sign of the QBO signatures we inferred for integrated quantities above. In the averages only easterlies $>|4| \mathrm{m} \mathrm{s}^{-1}$ are considered.

The size distribution curves (top panels) do not differ much due to the double logarithmic scale. The relative differences between the curves (bottom panels), however, show sufficiently large QBO signatures, which are consistent with our findings from integrated parameters. In particular they correspond well with mode-wise integrated number densities (Fig. 10): At $10 \mathrm{hPa}$, more aerosols (except in the coarse mode) are found when the zonal wind tendency is positive (black curve). This corresponds to positive anomalies in the Aitken and accumulation mode (Fig. 10d and f) in the month after the transition from the QBO westerly to the easterly phase. Nucleation and coarse-mode signatures are not significant at this level (Fig. 10a, g). At $40 \mathrm{hPa}$, larger concentrations are found during months when the easterly zonal wind is getting weaker (negative tendency, grey curve). This corresponds to positive anomalies in the Aitken and accumulation mode number densities in the month before the onset of the westerly zonal wind transition (Fig. 10d and f). Only aerosols of intermediate size, i.e. the largest Aitken mode and smallest accumulation mode particles, are inversely modulated. Here, the 7-month phase lag of accumulation mode QBO signatures, with respect to the Aitken mode, are cancelling out respective signatures in the size distribution averages. In contrast to $10 \mathrm{hPa}$ the signature in the nucleation mode is statistically significant; in addition BHN may be triggered by the QBO in their easterly phase (Fig. 10b).

The exemplarily shown size distributions and their relative changes also contain the imprint of QBO modulations in the microphysical processes, as discussed above, and correspond to signatures in the surface area density (Sect. 3.2.1): At the lower level, condensation is strong and shows a positive anomaly when $\mathrm{d} U_{\mathrm{EQBO}} / \mathrm{d} t<0$ (month with accelerating easterlies; compare anomalies in Fig. 11d). Accordingly, the SAD is positively modulated. Particularly, the effect is larger when the SAD is inferred for the entire range of aerosols (Fig. 7b) and weaker in the adopted size range with $R \geq 50 \mathrm{~nm}$ (Fig. 7d). At $10 \mathrm{hPa}$, condensation is approximately still 1 order of magnitude stronger than evaporation in the time mean (Fig. 11c, e). This is also reflected in the size distributions, where the positively modulated condensational growth during months when $\mathrm{d} U_{\mathrm{EQBO}} / \mathrm{d} t<0$ causes a shift of fine-mode aerosols to the right (grey curve). However, this growth is likely to be competing with coagulation. That is because coagulation causes the net loss in the number concentration for aerosols with $R<50 \mathrm{~nm}$ (note that $\mathrm{H}_{2} \mathrm{SO}_{4}$ condensation is aerosol number conserving), see also discussion in Sect. 3.4.4.

Unequally distributed QBO signatures in the size distributions also refer to the above-mentioned nonlinear coupling between the processes which determine the size distribution's shape, and, in turn, QBO signatures in the different aerosol modes and various properties - hence supporting our view that only by consideration of the QBO is the variability of the lower stratospheric aerosol layer in the tropical LS modelled adequately. Otherwise a comparably static Junge layer with a distinctly different life cycle of aerosols is simulated, with possibly false implications. 

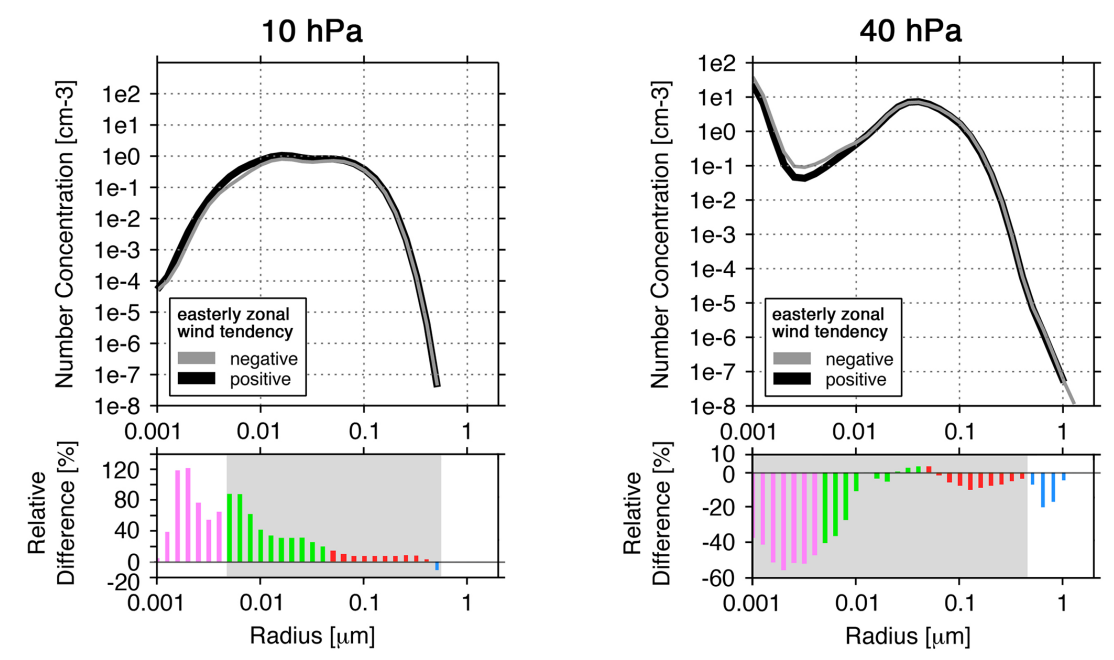

Figure 13. Comparison of modelled aerosol size distributions and associated QBO modulations, exemplarily at the 10 and $40 \mathrm{hPa}$ pressure levels. Inferred from monthly mean zonal means during the easterly phase of the QBO, when imposed anomalies in the integrated number densities (Fig. 10) may be phase shifted relative to the sign of the zonal wind tendency $\mathrm{d} U_{\mathrm{EQBO}} / \mathrm{d} t$. Bottom panels show corresponding relative differences between the two size distributions in each panel above and are binned according the particle's size discretisation of the microphysical scheme (calculated relative to the negative tendencies' average, i.e. the grey curve in the panels above). Grey shades in the bottom panel refer to those modes of the size distribution, where statistically significant QBO modulations have been determined in the integrated number densities according the standard Student's $t$-test.

\subsection{Precursor gases}

Previous work has already addressed some aspects of the natural variability of aerosol precursors in the stratosphere. HOM11, for example, discussed in detail how the QBO-free model predicts the aerosol precursors $\mathrm{SO}_{2}$ and sulfuric acid vapour in the stratospheric background in comparison to observations. Brühl et al. (2012) analysed the modelled shortterm variability of $\mathrm{SO}_{2}$ and sulfuric acid vapour with respect to oxidising capabilities of OCS in the volcanically quiescent stratosphere from 1999 and 2002. But Brühl et al. (2012) did not in greater detail investigate the coupling between the aerosol layer, the precursors and the QBO.

Generally, little is known about the vertical profiles of $\mathrm{SO}_{2}$ and $\mathrm{H}_{2} \mathrm{SO}_{4}$ vapour in the stratosphere. Most measurements were conducted in the early years of systematic exploration of the stratosphere (SPARC/ASAP, 2006; Mills et al., 2005, HOM11). During the last two decades the majority of observations of sulfur-bearing gases were conducted in the troposphere. According to SPARC/ASAP (2006) less than a quarter of the campaigns measured in the lowermost stratosphere. In the more recent years, $\mathrm{SO}_{2}$ measurements were conducted on a more regular basis, e.g. when aircraft campaigns touched the lowermost stratosphere (e.g. during SOLVE). But those are predominately confined to the lowermost regions of the mid- and high latitudes, so that they cannot be taken into consideration within this study that focus on the tropical LS. Above $30 \mathrm{~km}$, data from only one campaign were available until last year (2013) - which measured $\mathrm{SO}_{2}$ in the NH subtropics (ATMOS infrared spectrom- eter on a NASA Space Shuttle in 1985; Rinsland et al., 1995). Recently a climatology of monthly and zonal mean profiles of $\mathrm{SO}_{2}$ volume mixing ratios has been derived from Envisat/MIPAS measurements in the altitude range $15-45 \mathrm{~km}$ for the period from July 2002 to April 2012 (Höpfner et al., 2013). We compare to this data set below. Only a few extratropical data are available for $\mathrm{H}_{2} \mathrm{SO}_{4}$ vapour and are discussed in Mills et al. (2005) and HOM11.

In the model, the climatological mean $\mathrm{SO}_{2}$ mixing ratio (Fig. 14a) rapidly decreases from the TTL to $\sim 50 \mathrm{hPa}$ due to rapid photochemical conversion to $\mathrm{H}_{2} \mathrm{SO}_{4}$. Above $50 \mathrm{hPa}$, the mixing ratio increases due to the oxidation of OCS. Above $10 \mathrm{hPa}$ the photolysis of $\mathrm{H}_{2} \mathrm{SO}_{4}$ vapour establishes an upper-stratospheric reservoir of $\mathrm{SO}_{2}$, which plays a large role in the triggering of new aerosol formation in the polar spring stratosphere when the sunlight returns (Mills et al., 1999, 2005; Campbell et al., 2014, HOM11). The MIPAS profile varies much less than the modelled one. Quantitatively, MIPAS mixing rations are an order of magnitude larger around $40 \mathrm{hPa}$ and factor of 2 larger between 25 and $7 \mathrm{hPa}$. The origin of this discrepancy remains unclear. But since both Höpfner et al. (2013) and HOM11 (CTL simulation) emphasised a good agreement to the subtropical SPACELAB3/ATMOS SO2 profile $\left(26-32^{\circ} \mathrm{N}\right)$, potentially our model overestimates the annual cycle in the tropical $\mathrm{SO}_{2}$ profile, the photochemical $\mathrm{SO} 2$ oxidation, or both. On the other hand, we cannot prove tropical MIPAS profiles in more detail since other continuous measurements well above the TTL do not exist. Further investigations and other data sources are needed to understand this behaviour. 
a) $5 \mathrm{~N}-5 \mathrm{~S}$ Clim. Mean

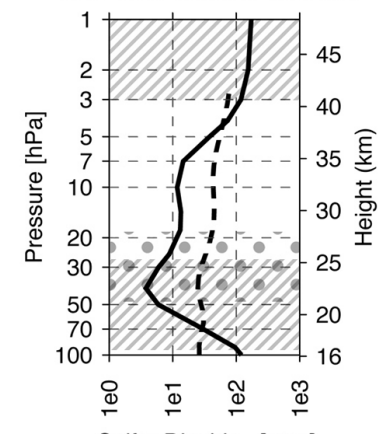

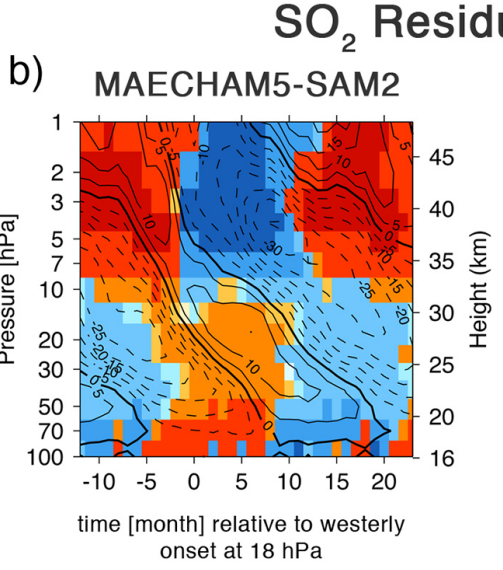

$\mathrm{SO}_{2}$ Residual Anomalies

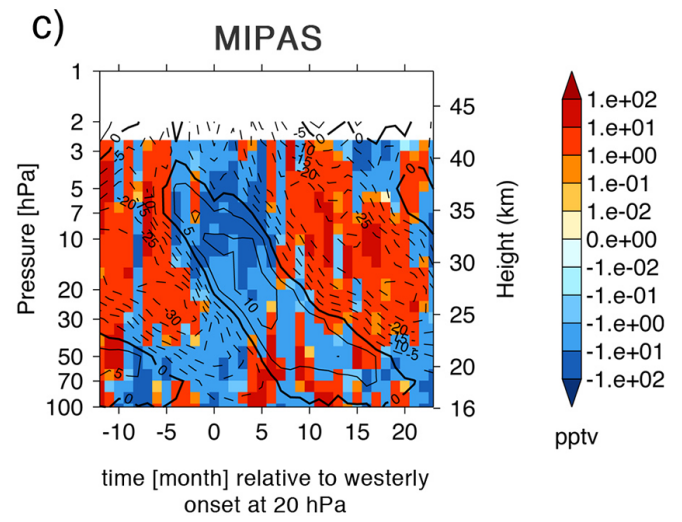

Figure 14. Comparison between the modelled $\mathrm{SO}_{2}$ mass mixing ratio and Envisat/MIPAS observations from Höpfner et al. (2013). (a) Climatological mean profiles. The continuous line represents the model simulation and the dashed line MIPAS observations. Panels (b) and (c) show composited residual anomalies from the model and MIPAS, relative to the onset of residual westerlies at $18 \mathrm{hPa}$ and $20 \mathrm{hPa}$, respectively. As before, model data are averaged between $5^{\circ} \mathrm{N}$ and $5^{\circ} \mathrm{S}$ for the years 1996-2006. MIPAS data have been obtained from the time series of measurements between July 2002 and April 2012. Composited zonal mean zonal wind contour lines in (c) have been obtained from the ECMWF ERA-Interim climatology, similarly to Figs. 2a and 8b. Pressure levels where QBO modulations are statistically significant are shaded grey. Hashed areas for the model and stippled for MIPAS.

a)

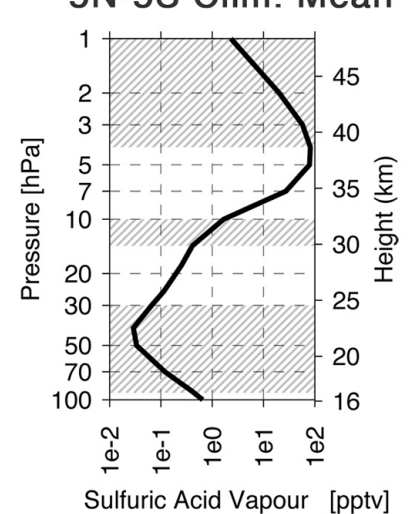

b)

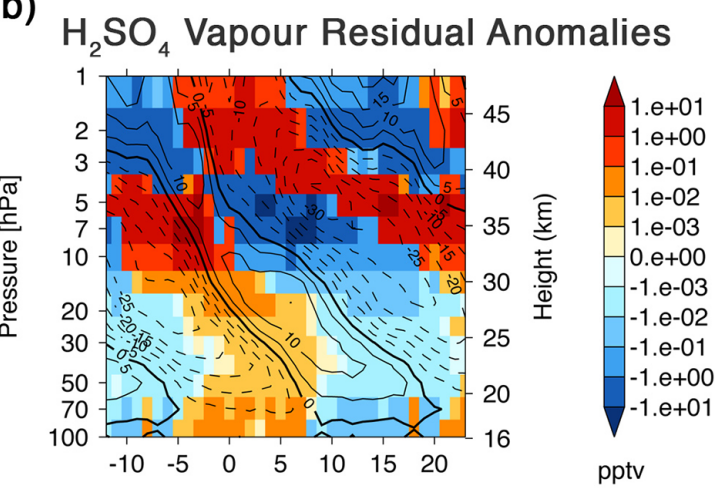

time [month] relative to westerly onset at $18 \mathrm{hPa}$

Figure 15. As in Fig. 6, except for the modelled $\mathrm{H}_{2} \mathrm{SO}_{4}$ vapour mass mixing ratio.

The modelled climatological mean tropical $\mathrm{H}_{2} \mathrm{SO}_{4}$ vapour mixing ratio profile (Fig. 15a) exhibits a minimum slightly above the $50 \mathrm{hPa}$ pressure level, where the vapour rapidly condenses onto aerosols. Above $50 \mathrm{hPa}$, the saturation vapour pressure of $\mathrm{H}_{2} \mathrm{SO}_{4}$ rapidly increases (between 50 and $10 \mathrm{hPa}$ by 7 orders of magnitude) so that with increasing altitude less vapour condenses and most of it remains in the gas phase. Above $20 \mathrm{hPa}$, the probability of droplet evaporation gradually increases with height, so that the gradient in the sulfuric acid vapour mixing ratio further increases to around the $5 \mathrm{hPa}$ level. That is the altitude where $\mathrm{H}_{2} \mathrm{SO}_{4}$ photolysis to $\mathrm{SO}_{3}$ becomes important (Burkholder and McKeen, 1997). $\mathrm{SO}_{3}$ in turn is photolysed to $\mathrm{SO}_{2}$ and builds up the $\mathrm{SO}_{2}$ reservoir in the upper stratosphere. This is seen in most of the stratosphere-resolving (chemistry-) climate models with an interactive aerosol component (Turco et al., 1979; Weisenstein et al., 1997; Mills et al., 2005, HOM11). Envisat/MIPAS observations recently confirmed the existence of such a reservoir (Höpfner et al., 2013), which had been already indicated by ATMOS measurements in spring 1985 at Northern Hemispheric subtropical latitudes. Above $45 \mathrm{~km}$, however, the ATMOS profile implies a further sink for $\mathrm{SO}_{2}$ near the stratopause by largely decreasing mixing ratios above $48 \mathrm{~km}(\sim 1 \mathrm{hPa})$, that is not confirmed by most models.

As seen from Fig. 14b and c, as well as from Fig. 15b, the QBO similarly modulates to a large degree $\mathrm{SO}_{2}$ and $\mathrm{H}_{2} \mathrm{SO}_{4}$ vapour in the equatorial stratosphere. Just above the TTL we found deviations from the modelled climatological mean of up to $\pm 20 \%$. Above $20 \mathrm{hPa}$, the relative QBO sig- 
nature may reach $\pm 50 \%$. While below $50 \mathrm{hPa}$, positive (negative) anomalies correlate with easterly (westerly) winds, the anomalies above relate to the QBO shear, and hence are in phase with the QBO temperature signal. A phase shift in the anomalies is found at approximately $10 \mathrm{hPa}$ in $\mathrm{SO}_{2}$ and in $\mathrm{H}_{2} \mathrm{SO}_{4}$ vapour around the $3 \mathrm{hPa}$ pressure level.

QBO anomalies in the tropical MIPAS $\mathrm{SO}_{2}$ climatology are relatively irregular below the $50 \mathrm{hPa}$ pressure level. Here, volcanic perturbations may have an imprint in the derived QBO signature. It is not trivial to remove such irregularly appearing pattern from the climatology, because such signatures disperse spatially, propagate up in-time, and generally decay in strength due to the relatively small chemical time constant ( $\sim 1$ month; SPARC/ASAP, 2006). More research is needed to establish a robust quantification method for the different factors determining the characteristics of the observed $\mathrm{SO}_{2}$ time series. Although above $50 \mathrm{hPa}(\sim 20 \mathrm{~km})$ the volcanic imprint is still detectable in the climatology (Höpfner et al., 2013, bottom panels in their Figs. 4 and 5), we infer well-defined QBO anomalies which correlate well with the $\mathrm{QBO}$ wind regime. This is different in the simulation, where $\mathrm{SO}_{2}$ anomalies above $20 \mathrm{hPa}$ lag behind the occurrence of strongest zonal winds. The relative strength of the anomalies is approximately similar in both data sets. Höpfner et al. (2013) reported QBO signatures in their MIPAS climatology as large as $30-50 \%$, relative to the climatological mean, being in good agreement with our analysis. MIPAS QBO anomalies are significant only between $50-18 \mathrm{hPa}$, whereas modelled anomalies are significant between $90-30 \mathrm{hPa}$ and above $3 \mathrm{hPa}$. At this point, we do not understand in particular the lag of the MIPAS anomalies relative to the model. Differences in the phase shifts of the inferred anomalies in the vertical are explained by the different shapes of the profiles. As mentioned above, the modelled photochemistry and/or model deficits in the representation of the annual cycle of the tropical upwelling may explain, at least parts, of the described differences in the inferred QBO signatures.

Below the QBO easterly jet, upwelling is enhanced (Gray and Chipperfield, 1990; Seol and Yamazaki, 1998), hence positive precursor anomalies below $50 \mathrm{hPa}$ depict an enhanced vertical transport through the TTL in the model. To what extent $\mathrm{H}_{2} \mathrm{SO}_{4}$ vapour is transported from the free troposphere into the LS remains speculative, because the small chemical time constant of $\mathrm{H}_{2} \mathrm{SO}_{4}$ vapour in the $\mathrm{LS}(\sim 1$ day) implies that $\mathrm{H}_{2} \mathrm{SO}_{4}$ vapour anomalies may appear as fingerprint structures of the $\mathrm{SO}_{2}$ anomalies. This is also supported by the kinetics of the $\mathrm{H}_{2} \mathrm{SO}_{4}$ vapour forming reaction between $\mathrm{SO}_{3}$ (oxidised from $\mathrm{SO}_{2}$ ) and $\mathrm{H}_{2} \mathrm{O}$, that depend exponentially on $1 / T$ (Sander et al., 2006), hence benefit from cold anomalies induced in the cold lowermost tropical stratosphere during QBO east phases.

Above $50 \mathrm{hPa}$, where modelled anomalies in both gases correlate well with the equatorial QBO temperature signal, it seems plausible that some of the $\mathrm{H}_{2} \mathrm{SO}_{4}$ vapour anomalies arise implicitly from the QBO-modulated $\mathrm{SO}_{2}$ oxida- tion. Phase reversal of the anomalies occurs where the mixing ratio profile distinctly changes shape, thus indicating that QBO-modulated advective transport accounts for most of the calculated QBO anomalies in the two precursor gases.

Furthermore, modelled QBO anomalies in the two precursor gases are in phase with modulations in the Aitken mode aerosol number density (Fig. 10d) and the $\mathrm{H}_{2} \mathrm{SO}_{4}$ vapour condensing onto aerosols (Fig. 11d). This implies that preexistent or newly formed aerosols rapidly grow by $\mathrm{H}_{2} \mathrm{SO}_{4}$ condensation, even though the strength of condensation decreases rapidly with height (Fig. 11c). Together with in-phase anomalies in the nucleation rate and nucleation mode number density around $50 \mathrm{hPa}$, this result indicates that, at least partly, the origin of Aitken mode aerosols in the LS is not the free troposphere, from where they have been more rapidly uplifted when the QBO phase is easterly. However, we cannot provide a more detailed quantification of pathways maintaining the volcanically quiescent aerosol layer in the tropical stratosphere, because it requires that OCS, one of the major sulfur sources in the LS (e.g. SPARC/ASAP, 2006), needs to be treated prognostically (e.g. Brühl et al., 2012). As a caveat it should be mentioned that the use of climatological mean oxidant fields likely affect the simulated QBO signature in the precursors, since these fields do not contain an inherent QBO variation due to averaging. The response of modelled precursor mixing ratios to QBO signatures in oxidant fields in a prospective interactively coupled middle atmospherechemistry-aerosol model could be damping, amplification or compensation and depend on phase of the signatures. With our model configuration we are not able to address this issue and further studies with such fully interactive model systems are needed to understand the coupling between the oxidising pathway from precursors to sulfate aerosols via $\mathrm{O}_{x}, \mathrm{OH}$, and $\mathrm{NO}_{2}$ and the $\mathrm{QBO}$.

\section{Conclusions}

Here, for the first time, we provide model-based indications for concurrent QBO-imposed effects in the tropical stratospheric aerosol layer that modulate the aerosol size distribution in a nonlinear manner. Such effects have only been suggested so far from satellite-measured aerosol extinction coefficients (Trepte and Hitchman, 1992) and $\mathrm{SO}_{2}$ measurements (Höpfner et al., 2013). Eleven years (1996-2006) of the post-Pinatubo stratospheric background were simulated with the aerosol-coupled middle-atmosphere circulation model MAECHAM5-SAM2. The data were examined with regard to the long-term variability of aerosol and precursors in the tropical lower stratosphere and variations caused by the QBO in aerosol dynamics and composition. We compared the data to a control simulation that did not resolve the QBO (HOM11), to merged data sets from observations of the solar occultation SAGE II satellite sensor and the space- 
borne CALIOP lidar and to the MIPAS observations of $\mathrm{SO}_{2}$ from Höpfner et al. (2013).

There is a general agreement that the QBO is an important forcing mechanism of the Earth's climate (e.g. Baldwin et al., 2001; Brönnimann, 2007) and largely determines the global dispersion of stratospheric trace constituents (see Baldwin et al., 2001). However, accompanying effects on sulfate aerosol droplets that form the Junge layer in the stratosphere have not yet been addressed in detail. Since this paper is a first attempt to examine the QBO-aerosol microphysics relationship in the tropical LS, we utilise a model system of reduced complexity with respect to the stratospheric aerosol system. We concentrate here on the simulation of sulfate aerosols since they dominate the stratospheric aerosol load. Other particulate substances might however have an impact on stratospheric dynamics as well. A more detailed understanding of the dynamics of sulfate aerosols in the tropical LS is also of particular interest for research on the separation of volcanic signatures from the natural variability of the stratospheric background, and is, therefore, a necessary step towards a better understanding of the aerosol behaviour in the LS as observed in the recent past. We have shown that in the model the tropical Junge layer is influenced by the QBO. The vertical expansion of the modelled layer, i.e. its thickness, differs by at least $5 \mathrm{~km}$ dependent on the phase of the QBO. This is in agreement with satelliteobserved aerosol extinctions and derived aerosol sizes, and hence does not arise solely from volcanic disturbances of the tropical lower stratosphere as argued by Hasebe (1994). This is important for understanding the climatological relevance of stratospheric background aerosols, which is still debated (e.g. Hofmann, 1990; Deshler et al., 2006; Solomon et al., 2011; Neely et al., 2013).

We found that the QBO affects all parameters we diagnosed from the model's aerosol scheme. Our results indicate that QBO effects in the sulfate droplet composition are small and depend almost linearly on the QBO signature in the tropical stratospheric temperature. QBO modulations in the modelled aerosol mixing ratio and size appear to be stronger and increase in the upper levels of the Junge layer (above $20 \mathrm{hPa}$ ), where the droplets evaporate. In particular at these altitudes we found clear indications for nonlinear relationships in the aerosol processing due to the influence of the QBO. Furthermore, and in agreement with other studies, we found an enhanced upwelling of $\mathrm{SO}_{2}$ into the lower stratosphere below the $50 \mathrm{hPa}$ pressure level when the QBO is in its easterly phase. Our model indicates that this modulation in the supply of the $\mathrm{SO}_{2}$ precursor establishes a chain of subsequent in-phase modulations in other modelled quantities below $50 \mathrm{hPa}$. The sulfuric acid vapour concentration is enhanced during easterly QBO and also the subsequent condensation onto intermediate-sized aerosols in the Aitken mode. QBO signatures in $\mathrm{SO}_{2}$ are quantitatively in agreement with MIPAS observations from Höpfner et al. (2013) above the $50 \mathrm{hPa}$ pressure level. However, it is not yet clear from our comparison, why the tropical climatological mean profiles differ substantially in their vertical shape. This difference may be responsible for the phase-lag of the QBO signatures between the model and MIPAS. The reduction of the stratospheric chemistry system to the sulfur cycle and precalculated monthly mean oxidant fields may partly explain the differences, but it should be noted that our model's $\mathrm{SO}_{2}$ profile is in the bulk of solutions from global stratospheric aerosol models. Other systematically observed $\mathrm{SO}_{2}$ profile climatologies do not exist for the stratosphere, so that more research is needed to better understand this issue.

Compared to the CTL experiment, where the Junge layer behaves almost statically, the nature of the more realistically predicted Junge layer in the QBO experiment is predicted to be highly variable. Prevailing westerly zonal winds expand the layer in the vertical. This motion subsequently is backed by an adiabatic uplift of aerosols in the anomalously cold QBO easterly shear. With progressing downward motion of descending easterly zonal winds, the entire layer descends and vertically diverges due to advection imposed by the QBO meridional circulation overlying the BDC. Before the QBO westerly jet propagates through the layer, reduced upwelling below the jet is further displacing the layer down to lower altitudes, where the layer has its smallest vertical extension.

Resulting anomalies in the modelled tropical aerosol mixing ratio are very similar to those observed in ozone. Hence they are dominated by QBO effects on the advective transport and are confined by the structure of the tropical mixing ratio profile. In the upper levels of the Junge layer, integrated aerosol size quantities are much more strongly modulated by the QBO than the bulk mixing ratio because imposed effects on microphysical processes play a larger role than further below. This view is confirmed by QBO signatures in the CCMI $\mathrm{SAD}$, a merged data set derived from satellite observations of aerosol extinction coefficients and backscatter from the SAGEII and CALIOP instruments. In particular in the evaporation region of the Junge layer the statistically significant signatures agree well. Below that level anomalies in the observation data set are significantly stronger than in the model ( $\sim 60 \%)$, presumably due to volcanic signatures.

The model predicts that the QBO modulates the balance of the mass transfer of $\mathrm{H}_{2} \mathrm{SO}_{4}$ vapour between the gas and the droplet's liquid phase. The mass transfer is shifted towards evaporation in the QBO-nudged model, compared to the CTL simulation. However, in the time average, evaporation is continuously accompanied by recurring condensation of $\mathrm{H}_{2} \mathrm{SO}_{4}$ onto the aerosols. The model indicates that below the evaporation region nucleation of particles is triggered by the QBO and may significantly influence the aerosol size distribution. However, this result strongly relies on use of the Vehkamäki parameterisation of binary homogeneous nucleation of the water and sulfuric acid mixture in the model. 
Our simulation shows that the life cycle of sulfate droplets in the tropical LS is determined by processes which are coupled in a strongly nonlinear manner to the QBO. This is because imposed QBO signatures in the different aerosol properties (i) differ in strength, (ii) differ over the size range of aerosols, (iii) are a function of altitude, and (iv) may be shifted in phase. It is clear that, away from the equatorial belt, QBO signatures in LS aerosol may show other signatures and couplings due to phase shift of the extratropical QBO signal, which also weakens poleward (Baldwin et al., 2001). QBO effects on the extratropical Junge layer were not within the scope of this study. Further studies follow to examine respective relationships.
The complexity of the described interactions between the QBO and the Junge layer in the model might be a key aspect in attempts to understand the global impact of stratospheric aerosols. It may also help to assess the discrepancy between modelled and observed aerosol quantities in periods when the stratosphere is largely unperturbed by sporadic injections from volcanoes or other sources. Although not addressable with this model configuration, the catalytic cycles that destroy wintertime polar stratospheric ozone may respond to QBO effects in the Junge layer. And, moreover, it seems likely that such effects may feed back into the climate system, further complicating the comprehensive understanding of the aerosol system in the UTLS. 
Appendix A: Abbreviations

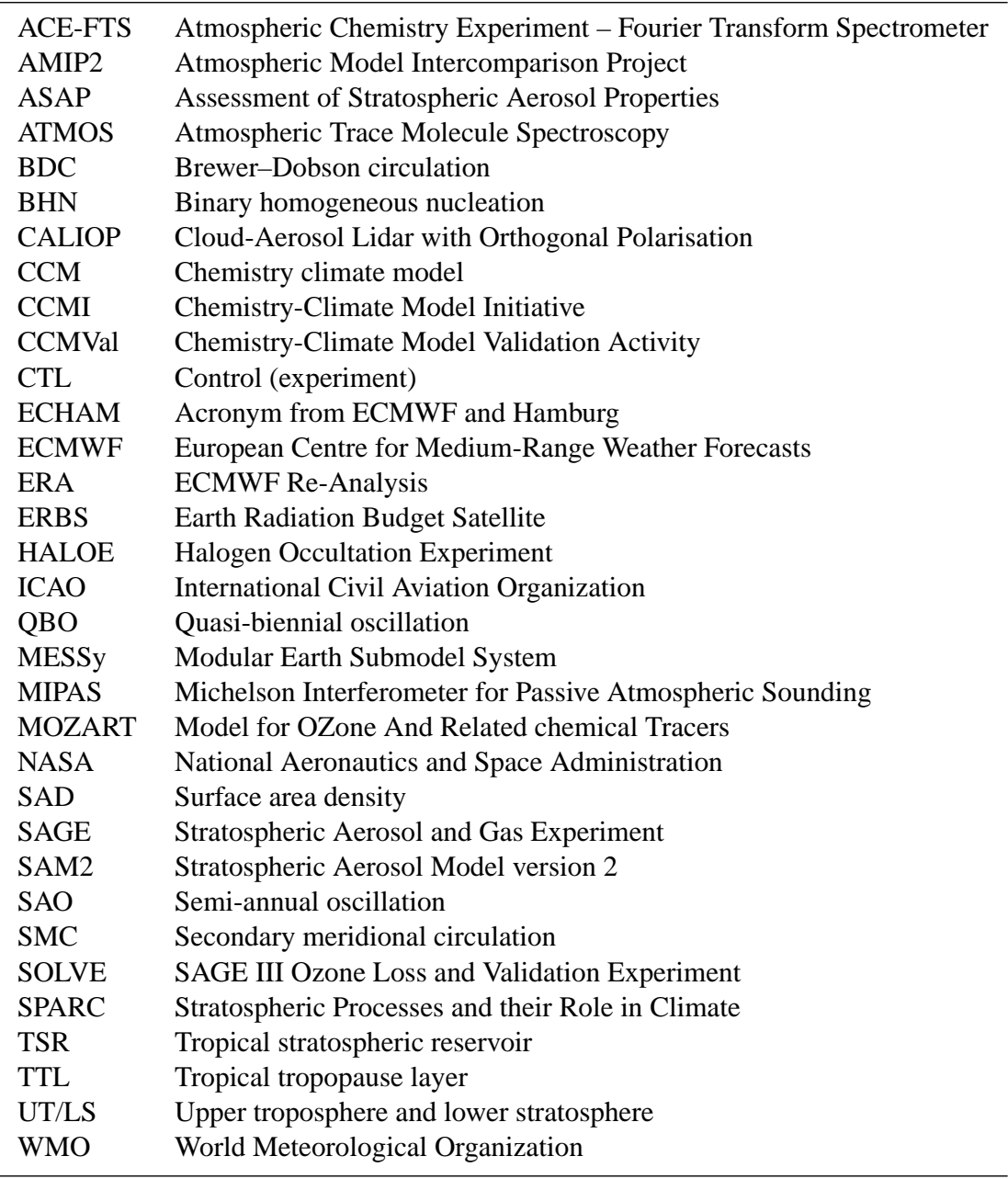


Acknowledgements. We wish to acknowledge Christian von Savigny, Lena A. Brinkhoff, Beiping Luo, Abhay Devasthale, Hauke Schmidt, Steffan Kinne, Hartmut Graß1, Ulrike Niemeier and Kathryn Emmerson on their helpful comments on the paper. We thank the two anonymous reviewers for their valuable comments and suggestions. We also gratefully acknowledge Michael Hoepfner (and the KIT) for providing the MIPAS data and his kind help. Simulations were done at the German Climate Computer Centre (DKRZ). Parts of the work have been funded by the German Federal Ministry of Education and Research (BMBF) under the projects ROSA (FKZ: 01LG1212A) and MIKLIP (FKZ: 01LP1130A).

The article processing charges for this open-access publication were covered by the Max Planck Society.

Edited by: A. Engel

\section{References}

Andrews, D. G., Holton, J. R., and Leovy, C. B.: Middle Atmosphere Dynamics, Academic Press, San Diego, CA, 1987.

Arfeuille, F., Luo, B. P., Heckendorn, P., Weisenstein, D., Sheng, J. X., Rozanov, E., Schraner, M., Brönnimann, S., Thomason, L. W., and Peter, T.: Modeling the stratospheric warming following the Mt. Pinatubo eruption: uncertainties in aerosol extinctions, Atmos. Chem. Phys., 13, 11221-11234, doi:10.5194/acp13-11221-2013, 2013.

Baldwin, M. P. and Gray, L. J.: Tropical stratospheric zonal winds in ECMWF ERA-40 reanalysis, rocketsonde data, and rawinsonde data, Geophys. Res. Lett., 32, L09806, doi:10.1029/2004GL022328, 2005.

Baldwin, M. P., Gray, L. J., Dunkerton, T. J., Hamilton, K., Haynes, P. H., Randel, W. J., Holton, J. R., Alexander, M. J., Hirota, I., Horinouchi, T., Jones, D. B. A., Kinnersley, J. S., Marquardt, C., Sato, K., and Takahashi, M.: The quasi-biennial oscillation, Rev. Geophys., 39, 179-229, 2001.

Barnes, J. E. and Hofmann, D. J.: Variability in the stratospheric background aerosol over Mauna Loa observatory, Geophys. Res. Lett., 28, 2895-2898, 2001.

Bauman, J. J., Russell, P. B., Geller, M. A., and Hamill, P.: A stratospheric aerosol climatology from SAGE II and CLAES measurements: 1. Methodology, J. Geophys. Res., 108, 4382, doi:10.1029/2002JD002992, 2003a.

Bauman, J. J., Russell, P. B., Geller, M. A., and Hamill, P.: A stratospheric aerosol climatology from SAGE II and CLAES measurements: 2. Results and comparisons, 1984-1999, J. Geophys. Res., 108, 4383, doi:10.1029/2002JD002993, 2003b.

Bourassa, A. E., Robock, A., Randel, W. J., Deshler, T., Rieger, L. A., Lloyd, N. D., Llewellyn, E. J. T., and Degenstein, D. A.: Large Volcanic Aerosol Load in the Stratosphere Linked to Asian Monsoon Transport, Science, 337, 78-81, doi:10.1126/science.1219371, 2012.

Brönnimann, S.: The impact of El Niño-Southern Oscillation on European climate, Rev. Geophys., 45, RG3003, doi:10.1029/2006RG000199, 2007.

Brühl, C., Lelieveld, J., Crutzen, P. J., and Tost, H.: The role of carbonyl sulphide as a source of stratospheric sulphate aerosol and its impact on climate, Atmos. Chem. Phys., 12, 1239-1253, doi:10.5194/acp-12-1239-2012, 2012.

Burkholder, J. B. and McKeen, S.: UV absorption cross sections for $\mathrm{SO}_{3}$, Geophys. Res. Lett., 24, 3201-3204, 1997.

Butchart, N., Scaife, A. A., Austin, J., Hare, S. H. E., and Knigh, J. R.: Quasi-biennial oscillation in ozone in a coupled chemistry-climate model, J. Geophys. Res., 108, 4486, doi:10.1029/2002JD003004, 2003.

Campbell, P., Mills, M. J., and Deshler, T.: The global extent of the mid stratospheric CN layer: A three-dimensional modeling study, J. Geophys. Res., 119, 1015-1030, doi:10.1002/2013JD020503, 2014.

Choi, W., Grant, W. B., Park, J. H., Lee, K., Lee, H., and Russell III, J. M.: Role of the quasi-biennial oscillation in the transport of aerosols from the tropical stratospheric reservoir to midlatitudes, J. Geophys. Res., 103, 6033-6042, 1998.

Choi, W., Lee, H., Grant, W. B., Park, J. H., Holton, J. R., Lee, K.M., and Naujokat, B.: On the secondary meridional circulation associated with the quasi-biennial oscillation, Tellus B, 54, 395406, 2002.

Damadeo, R. P., Zawodny, J. M., Thomason, L. W., and Iyer, N.: SAGE version 7.0 algorithm: application to SAGE II, Atmos. Meas. Tech., 6, 3539-3561, doi:10.5194/amt-6-3539-2013, 2013.

Dentener, F., Kinne, S., Bond, T., Boucher, O., Cofala, J., Generoso, S., Ginoux, P., Gong, S., Hoelzemann, J. J., Ito, A., Marelli, L., Penner, J. E., Putaud, J.-P., Textor, C., Schulz, M., van der Werf, G. R., and Wilson, J.: Emissions of primary aerosol and precursor gases in the years 2000 and 1750 prescribed data-sets for AeroCom, Atmos. Chem. Phys., 6, 4321-4344, doi:10.5194/acp-64321-2006, 2006.

Deshler, T., Hervig, M. E., Hofmann, D. J., Rosen, J. M., and Liley, J. B.: Thirty years of in situ stratospheric aerosol size distribution measurements from Laramie, Wyoming $\left(41^{\circ} \mathrm{N}\right)$, using balloon-borne instruments, J. Geophys. Res., 108, 4167, doi:10.1029/2002JD002514, 2003.

Deshler, T., Anderson-Sprecher, R., Jäger, H., Barnes, J., Hofmann, D. J., Clemesha, B., Simonich, D., Osborn, M., Grainger, R. G., and Godin-Beekmann, S.: Trends in the nonvolcanic component of stratospheric aerosol over the period 1971-2004, J. Geophys. Res., 111, D01201, doi:10.1029/2005JD006089, 2006.

Dubovik, O., Smirnov, A., Holben, B. N., King, M. D., Kaufman, Y. J., Eck, T. F., and Slutsker, I.: Accuracy assessments of aerosol optical properties retrieved from Aerosol Robotic Network (AERONET) Sun and sky radiance measurements, J. Geophys. Res., 105, 9791-9806, 2000.

English, J. M., Toon, O. B., Mills, M. J., and Yu, F.: Microphysical simulations of new particle formation in the upper troposphere and lower stratosphere, Atmos. Chem. Phys., 11, 9303-9322, doi:10.5194/acp-11-9303-2011, 2011.

English, J. M., Toon, O. B., and Mills, M. J.: Microphysical simulations of large volcanic eruptions: Pinatubo and Toba, J. Geophys. Res., 118, 1880-1895, doi:10.1002/jgrd.50196, 2013.

Eyring, V., Lamarque, J.-F., Hess, P., Arfeuille, F., Bowman, K., Chipperfield, M. P., Duncan, B., Fiore, A., Gettelman, A., Giorgetta, M. A., Granier, C., Kinnison, M. H. D., Kunze, M., Langematz, U., Luo, B., Martin, R., Matthes, K., Newman, P. A., Peter, T., Robock, A., Ryerson, T., Saiz-Lopez, A., Salawitch, R., Schultz, M., Shepherd, T. G., Shindell, D., Staehe- 
lin, J., Tegtmeier, S., Thomason, L., Tilmes, S., Vernier, J.-P., Waugh, D. W., and Young, P. J.: Overview of IGAC/SPARC Chemistry-Climate Model Initiative (CCMI) Community Simulations in Support of Upcoming Ozone and Climate Assessments, in: SPARC Newsletter 40, 48-66, WMO/SPARC, Zürich, 2013

Froyd, K. D., Murphy, D. M., Sanford, T. J., Thomson, D. S., Wilson, J. C., Pfister, L., and Lait, L.: Aerosol composition of the tropical upper troposphere, Atmos. Chem. Phys., 9, 4363-4385, doi:10.5194/acp-9-4363-2009, 2009.

Fueglistaler, S., Dessler, A. E., Dunkerton, T. J., Folkins, I., Fu, Q., and Mote, P. W.: Tropical tropopause layer., Rev. Geophys., 47, RG1004, doi:10.1029/2008RG000267, 2009.

Ghan, S. J. and Schwartz, S. E.: Aerosol properties and processes: A path from field and laboratory measurements to global climate models, Bull. Am. Meteor. Soc., 88, 1059-1083, doi:10.1175/BAMS-88-7-1059, 2007.

Gilman, D. L., Fuglister, F. J., and Mitchell Jr., J. M.: On the power spectrum of "red noise", J. Atmos. Sci., 20, 182-184, 1963.

Giorgetta, M. A. and Bengtsson, L.: Potential role of the quasibiennial oscillation in the stratosphere-troposphere exchange as found in water vapor in general circulation model experiments, J. Geophys. Res., 104, 6003-6019, 1999.

Giorgetta, M. A., Manzini, E., and Roeckner, E.: Forcing of the quasi-biennial oscillation from a broad spectrum of atmospheric waves, Geophys. Res. Lett., 29, 1245, doi:10.1029/2002GL014756, 2002.

Giorgetta, M. A., Manzini, E., Roeckner, E., Esch, M., and Bengtsson, L.: Climatology and forcing of the quasi-biennial oscillation in the MAECHAM5 model, J. Climate, 19, 3882-3901, 2006.

Grainger, R., Lambert, A., Rogers, C., Taylor, F., and Deshler, T.: Straospheric aerosol effective radius, surface area and volume estimated from infrared measurements, J. Geophys. Res., 100, 16507-16518, 1995

Grant, W., Browell, E. V., Long, C. S., and Stowe, I. I.: Use of volcanic aerosols to study the tropical stratospheric reservoir, J. Geophys. Res., 101, 3973-3988, 1996.

Gray, L. J. and Chipperfield, M. P.: On the interannual variability of trace gases in the middle atmosphere, Geophys. Res. Lett., 17, 933-936, 1990.

Hamill, P., Toon, O. B., and Kiang, C. S.: Microphysical processes affecting stratospheric aerosol particles, J. Atmos. Sci., 34, 1104-1119, 1977.

Hamill, P., Jensen, E. J., Russel, P. B., and Bauman, J. J.: The life cycle of stratospheric aerosol particles, Bull. Am. Meteor. Soc., 78, 1395-1410, 1997.

Hasebe, F.: Quasi-biennial oscillations of ozone and diabatic circulation in the equatorial stratosphere, J. Atmos. Sci., 51, 729-745, 1994.

Hofmann, D., Barnes, J., O'Neill, M., Trudeau, M., and Neely, R.: Increase in background stratospheric aerosol observed with lidar at Mauna Loa Observatory and Boulder, Colorado., Geophys. Res. Lett., 36, L15808, doi:10.1029/2009GL039008, 2009.

Hofmann, D. J.: Increase in the stratospheric background sulfuric acid aerosol mass in the past 10 years, Science, 248, 996-1000, 1990.

Holton, J. R., Haynes, P. H., McIntyre, M. E., Douglass, A. R., Rood, R. R., and Pfister, L.: Stratospheric-tropospheric exchange, Rev. Geophys., 33, 403-439, 1995.
Hommel, R.: Die Variabilität von stratosphärischem HintergrundAerosol, Eine Untersuchung mit dem globalen sektionalen Aerosolmodell MAECHAM5-SAM2, Ph.D. thesis, Universität Hamburg, 2008.

Hommel, R., Timmreck, C., and Graf, H. F.: The global middleatmosphere aerosol model MAECHAM5-SAM2: comparison with satellite and in-situ observations, Geosci. Model Dev., 4, 809-834, doi:10.5194/gmd-4-809-2011, 2011.

Höpfner, M., Glatthor, N., Grabowski, U., Kellmann, S., Kiefer, M., Linden, A., Orphal, J., Stiller, G., von Clarmann, T., Funke, B., and Boone, C. D.: Sulfur dioxide $\left(\mathrm{SO}_{2}\right)$ as observed by MIPAS/Envisat: temporal development and spatial distribution at 15-45 km altitude, Atmos. Chem. Phys., 13, 10405-10423, doi:10.5194/acp-13-10405-2013, 2013.

Horowitz, L. W., Walters, S., Mauzerall, D. L., Emmons, L. K., Rasch, P. J., Granier, C., Tie, X. X., Lamarque, J. F., Schultz, M. G., Orlando, G. S., and Brasseur, G. P.: A global simulation of tropospheric ozone and related tracers: Description and evaluation of MOZART, Version 2, J. Geophys. Res., 108, 4784, doi:10.1029/2002JD002853, 2003.

IPCC: Climate Change 2013: The Physical Science Basis, Contribution of Working Group I to the Fifth Assessment Report of the Intergovernmental Panel on Climate Change, edited by: Stocker, T. F., Qin, D., Plattner, G.-K., Tignor, M., Allen, S. K., Boschung, J., Nauels, A., Xia, Y., Bex, V., Midgley, P. M., Cambridge University Press, Cambridge, United Kingdom and New York, NY, USA, 1535 pp., 2013.

Jacobson, M. Z.: Fundamentals of atmospheric modeling, Cambridge University Press, Cambridge, 2nd Edn., 68 pp., 2005.

Jöckel, P., Sander, R., Kerkweg, A., Tost, H., and Lelieveld, J.: Technical Note: The Modular Earth Submodel System (MESSy) - a new approach towards Earth System Modeling, Atmos. Chem. Phys., 5, 433-444, doi:10.5194/acp-5-433-2005, 2005.

Junge, C. E., Chagnon, C. W., and Manson, J. E.: Stratospheric aerosols, J. Meteorol., 18, 81-108, 1961.

Kasten, F.: Falling speed of aerosol particles., J. Appl. Meteorol., 7, 944-947, 1968.

Lin, S. J. and Rood, R. B.: Multidimensional flux form semiLagrangian transport, Mon. Weather Rev., 124, 2046-2068, 1996.

Manzini, E., Giorgetta, M. A., Esch, M., Kornblueh, L., and Roeckner, E.: The influence of sea surface temperatures on the northern winter stratosphere: Ensemble simulations with the MAECHAM5 model, J. Climate, 19, 3863-3881, 2006.

Mills, M., Toon, O. B., and Solomon, S.: A 2D microphysical model of the polar stratospheric CN layer, Geophys. Res. Lett., 26, 1133-1136, 1999.

Mills, M., Toon, O., Vaida, V., Hintze, P., Kjaergaard, H., Schofield, D., and Robinson, T.: Photolysis of sulfuric acid vapor by visible light as a source of the polar stratospheric CN layer, J. Geophys. Res., 110, D08201, doi:10.1029/2004JD005519, 2005.

Mote, P. W., Rosenlof, K. H., Mclntyre, M. E., Carr, E. S., Gille, J. C., Holton, J. R., Kinnersley, J. S., Pumphrey, H. C., Russell III, J. M., and Waters, J. W.: An atmospheric tape recorder: The imprint of tropical tropopause temperatures on stratospheric water vapor, J. Geophys. Res., 101, 3989-4006, 1996.

Murphy, D. M., Cziczo, D. J., Hudson, P. K., and Thomson, D. S.: Carbonaceous material in aerosol particles in the lower strato- 
sphere and tropopause region, J. Geophys. Res., 112, D04203, doi:10.1029/2006JD007297, 2007.

Naujokat, B.: An update of the observed quasi-biennial oscillation of the stratospheric winds over the tropics, J. Atmos. Sci., 43, 1873-1877, 1986.

Neely, R. R. I., English, J. M., Toon, O. B., Solomon, S., Mills, M., and Thayer, J. P.: Implications of extinction due to meteoritic smoke in the upper stratosphere, Geophys. Res. Lett., 38, L24808, doi:10.1029/2011GL049865, 2011.

Neely, R. R. I., Toon, O. B., Solomon, S., Vernier, J.-P., Alvarez, C., English, J. M., Rosenlof, K. H., Mills, M. J., Bardeen, C. G., Daniel, J. S., and Thayer, J. P.: Recent anthropogenic increases in $\mathrm{SO} 2$ from Asia have minimal impact on stratospheric aerosol, Geophys. Res. Lett., 40, 1-6, doi:10.1002/grl.50263, 2013.

Neu, J. L., Sparling, L. C., and Plumb, R. A.: Variability of the subtropical "edges" in the stratosphere, J. Geophys. Res., 108, 4482, doi:10.1029/2002JD002706, 2003.

Niemeier, U., Timmreck, C., Graf, H.-F., Kinne, S., Rast, S., and Self, S.: Initial fate of fine ash and sulfur from large volcanic eruptions, Atmos. Chem. Phys., 9, 9043-9057, doi:10.5194/acp9-9043-2009, 2009.

Pitari, G., Mancini, E., Rizi, V., and Shindell, D. T.: Impact of future climate and emission changes on stratospheric aerosols and ozone, J. Atmos. Sci., 59, 414-440, 2002.

Plumb, R. A. and Bell, R. C.: A model of quasibiennial oscillation on an equatorial beta-plane, Q. J. R. Meteorol. Soc., 108, 335352, 1982.

Pruppacher, H. R. and Klett, J. D.: Micropysics of clouds and precipitation, D. Reidel, Dordrecht, 1979.

Rex, M., Timmreck, C., Kremser, S., Thomason, L., and Vernier, J.-P.: Stratospheric sulphur and its Role in Climate (SSiRC), in: SPARC Newsletter 39, p. 37, WMO/SPARC, Zürich, 2012.

Rinsland, C. P., Gunson, M. R., Ko, M. K. W., Weisenstein, D. W., Zander, R., Abrams, M. C., Goldman, A., Sze, N. D., and Yue, G. K.: $\mathrm{H}_{2} \mathrm{SO}_{4}$ photolysis: A source of sulfur dioxide in the upper stratosphere, Geophys. Res. Lett., 22, 1109-1112, 1995.

Roeckner, E., Baeuml, G., Bonaventura, L., Brokopf, R., Esch, M., Giorgetta, M., Hagemann, S., Kirchner, I., Kornblueh, L., Manzini, E., Rhodin, A., Schlese, U., Schulzweida, U., and Tompkins, A.: The atmospheric general circulation model ECHAM5 - Part I, Max Planck Institute for Meteorology, Hamburg, Germany, MPI Report No. 349, 2003.

Rosen, J. M.: The boiling point of stratospheric aerosols, J. Applied Meteor., 10, 1044-1045, 1971.

Sander, S., Friedl, R., Ravishankara, A., Golden, D., Kolb, C., Kurylo, M., Huie, R., Orkin, V., Molina, M., Moortgat, G., and Finlayson-Pitts, B.: Chemical Kinetics and Photochemical Data for Use in Atmospheric Studies, JPL Publication 06-2, Evaluation No 15, NASA Jet Propulsion Laboratory, California Institute of Technology, Pasadena, California, 2006.

Seinfeld, J. H. and Pandis, S. N.: Atmospheric chemistry and physics: From air pollution to climate change, 2nd Edn., WileyInterscience, New York, 2006.

Seol, D.-I. and Yamazaki, K.: QBO and Pinatubo signals in the mass flux at $100 \mathrm{hPa}$ and stratospheric circulation, Geophys. Res. Lett., 25, 1641-1644, 1998.

Society, R.: Geoengineering the climate, Science, governance and uncertainty, RS Policy Report 10/09, ISBN 978-0-85403-773-5, The Royal Society, London, 2009.
Solomon, S., Daniel, J. S., Neely, R. R., Vernier, J.-P., Dutton, E. G., and Thomason, L. W.: The Persistently Variable "Background" Stratospheric Aerosol Layer and Global Climate Change, Science, 333, 866-870, doi:10.1126/science.1206027, 2011.

SPARC/ASAP: WMO/SPARC Scientific Assessment of Stratospheric Aerosol Properties (ASAP), WCRP-124 WMO/TD- No. 1295, SPARC Report No. 4, edited by: Thomason, L. and Peter, Th., WMO, 2006.

Steele, H. M. and Hamill, P.: Effects of temperature and humidity on the growth and optical properties of sulfuric acid-water droplets in the stratosphere, J. Aerosol Sci., 12, 517-528, 1981.

Stier, P., Feichter, J., Kinne, S., Kloster, S., Vignati, E., Wilson, J., Ganzeveld, L., Tegen, I., Werner, M., Balkanski, Y., Schulz, M., Boucher, O., Minikin, A., and Petzold, A.: The aerosol-climate model ECHAM5-HAM, Atmos. Chem. Phys., 5, 1125-1156, doi:10.5194/acp-5-1125-2005, 2005.

Thomason, L. W., Burton, S. P., Luo, B.-P., and Peter, T.: SAGE II measurements of stratospheric aerosol properties at non-volcanic levels, Atmos. Chem. Phys., 8, 983-995, doi:10.5194/acp-8-9832008, 2008.

Timmreck, C.: Three-dimensional simulation of stratospheric background aerosol: First results of a multiannual general circulation model simulation, J. Geophys. Res., 106, 28313-28332, 2001.

Trepte, C. R. and Hitchman, M. H.: Tropical stratospheric circulation deduced from satellite aerosol data, Nature, 355, 626-628, 1992.

Turco, R. P., Hamill, P., Toon, O. B., Whitten, R. C., and Kiang, C. S.: A one-dimensional model describing aerosol formation and evolution in the stratosphere: I. physical processes and mathematical analogs, J. Atmos. Sci., 36, 699-717, 1979.

Vehkamäki, H., Kulmala, M., Napari, I., Lehtinen, K. E. J., Timmreck, C., Noppel, M., and Laaksonen, A.: An improved parameterization for sulfuric acid water nucleation rates for tropospheric and stratospheric conditions, J. Geophys. Res., 107, 4622-4632, 2002.

Vernier, J.-P., Thomason, L. W., Pommereau, J.-P., Bourassa, A., Pelon, J., Garnier, A., Hauchecorne, A., Blanot, L., Trepte, C., Degenstein, D., and Vargas, F.: Major influence of tropical volcanic eruptions on the stratospheric aerosol layer during the last decade, Geophys. Res. Lett., 38, L12807, doi:10.1029/2011GL047563, 2011.

Vernier, J.-P., Thomason, L. W., Fairlie, T. D., Minnis, P., Palikonda, R., and Bedka, K. M.: Comment on "Large Volcanic Aerosol Load in the Stratosphere Linked to Asian Monsoon Transport", Science, 339, p. 647, doi:10.1126/science.1227817, 2013.

von Storch, H. and Zwiers, F. W.: Statistical analysis in climate research, Cambridge University Press, Cambridge, 1999.

Weisenstein, D. K., Yue, G. K., Ko, M. K. W., Sze, N.-D., Rodriguez, J. M., and Scott, C. J.: A two-dimensional model of sulfur species and aerosols, J. Geophys. Res., 102, 13019-13035, 1997.

Wurl, D., Grainger, R. G., McDonald, A. J., and Deshler, T.: Optimal estimation retrieval of aerosol microphysical properties from SAGE II satellite observations in the volcanically unperturbed lower stratosphere, Atmos. Chem. Phys., 10, 4295-4317, doi:10.5194/acp-10-4295-2010, 2010.

Yue, G., Poole, L., Wang, P.-H., and Chiou, E.: Stratospheric aerosol acidity, density, and refractive index deduced from SAGE II and NMC temperature data, J. Geophys. Res., 99, 3727-3738, 1994. 